\title{
Charting the Life Course: Age Differences and Validity of Beliefs About Lifespan Development
}

\author{
Michaela Riediger, Manuel C. Voelkle, Sabine Schaefer, and Ulman Lindenberger \\ Max Planck Institute for Human Development, Berlin, Germany
}

\begin{abstract}
This study examined how children (9 years), adolescents (13 to 15 years), younger adults (21 to 26 years), and older adults ( 70 to 76 years) chart age gradients of cognitive and social functioning from childhood to old age. Participants $(N=156)$ rated typical performance levels in different life phases for 10 aspects of cognitive and social functioning. Compared with older participants, children expected lower performance levels and higher temporal stability, particularly during adulthood and into old age, and showed lower interindividual consensus in their ratings. Individuals in all 4 age groups recognized that fluid cognitive abilities reach their developmental peak earlier in life and decline more steeply thereafter than crystallized cognitive abilities. Older adults and, to a lesser extent, children evaluated their own current functioning as being better than that of their typical age peers. Furthermore, older adults charted typical cognitive development in middle and earlier late adulthood more positively than the participants in the other 3 age groups, which possibly reflects a partial externalization of their own positive self-views and a self-enhancing bias. Comparisons with life span gradients of cognitive performance (McArdle, Ferrer-Caja, Hamagami, \& Woodcock, 2002) suggest that the ratings of adolescents and younger adults were in better agreement with empirically observed average performance trajectories than the ratings of children and older adults. We conclude that beliefs about normative cognitive and social aspects of life span development emerge in late middle childhood, solidify into culturally shared scripts by mid-adolescence, and remain subject to further change into old age.
\end{abstract}

Keywords: beliefs about aging, cognitive development, social development, biexponential latent growth curve modeling, age differences

How good is a typical 80-year-old in solving interpersonal conflicts, in memorizing things, or in finding new friends? And what about typical 60-, 40-, 20-, or 10-year-olds? Many contemporary developmental-psychological studies investigate human development and aging in different areas of functioning. Comparatively less attention, however, has been paid to how individuals believe the development of different aspects of functioning unfolds throughout life, and whether there are agerelated differences in this respect. Such subjective representations of typical development are important, however, because they inform expectations of how one can, should, or will be like in certain phases of life. As such, they guide people's behavior, both consciously and subconsciously, and influence their agegraded attitudes toward, and interpretations of, themselves and others (Hess, 2006; Rothermund \& Brandtstädter, 2003). Ex-

Michaela Riediger, Max Planck Research Group Affect Across the LifeSpan, Max Planck Institute for Human Development, Berlin, Germany; Manuel C. Voelkle, Sabine Schaefer, and Ulman Lindenberger, Center for Lifespan Psychology, Max Planck Institute for Human Development.

Michaela Riediger and Manuel C. Voelkle contributed equally to this article and are listed in alphabetical order. We thank Rozalina Angelova, Dulce Erdt, Axinja Hachfeld, Viola Jucksch, and Sebastian Mohnke for their help with data collection, and Jan Steinkraus and Elmar Tampe for programming the study, Lisa Deunert for her help with preparing the tables, and Amy Michéle for editorial assistance.

Correspondence concerning this article should be addressed to Manuel C. Voelkle or Michaela Riediger, Max Planck Institute for Human Development, Lentzeallee 94, 14195 Berlin, Germany. E-mail: voelkle@mpibberlin.mpg.de or riediger@mpib-berlin.mpg.de pectations of pronounced decline in cognitive abilities in old age, for example, can provide impetus for taking compensatory or preparatory actions. It can also, however, contribute to older adults' diminished confidence in their intellectual capacity, which, in turn, may enhance their test anxiety and thus delimit their actual cognitive performance (Lineweaver \& Hertzog, 1998). Beliefs about typical development can also guide how individuals think about and act toward other people of various ages. It has been found, for example, that people tend to ascribe memory failure of unknown younger persons to lack of effort, but a comparable memory failure of unknown older persons to mental difficulty (Erber, Szuchman, \& Prager, 1997).

Beliefs about typical ("normal") human development include expectations about both the timing and sequencing of life events (e.g., graduation from school, marriage, or retirement; Rubin \& Berntsen, 2003) and the life span trajectories of given aspects of functioning (e.g., developmental growth and decline of cognitive or physical abilities; Heckhausen, Dixon, \& Baltes, 1989). The focus of the present article is on the latter, that is, on people's assumptions regarding whether, when, and how fast a given aspect of functioning is typically acquired and improved, whether and when it typically reaches its developmental peak, and whether, when, and how fast it typically declines.

Most of the prior empirical investigations have focused on beliefs about typical development during adulthood as held by adults. Investigations of beliefs about development in general (assessed across diverse aspects of functioning) indicate consensus across different adult age groups that the ratio of developmental gains (e.g., increase in world knowledge) to developmental losses (e.g., decline in sensory-motor functioning) gets smaller through- 
out adulthood (Heckhausen, 1999). Other studies have focused on beliefs about the typical development of more narrowly defined aspects of functioning. Cognitive abilities, and memory in particular, have been investigated most often. In line with developmental beliefs in general, adults of various ages assumed that both decline throughout adulthood. Differences in beliefs between age groups, when present, tended to be small. Overall, the observed differences suggest that older adults hold slightly more favorable expectations of typical adult development than younger adults do. Studies summarized by Heckhausen (1999), for example, found that older adults located the timing at which developmental losses start to outweigh developmental gains a little later during adulthood than younger individuals did. Similarly, Lineweaver and Hertzog (1998) found that older, compared with younger, participants tended to believe memory decline began somewhat later in adult life. Furthermore, there is also evidence that older adults hold more positive age stereotypes than later-born cohorts and have higher age thresholds for when to consider someone as being "old" (Kornadt \& Rothermund, 2011).

The present study aimed to extend this line of inquiry in three respects. First, we investigated beliefs about typical development throughout a larger segment of the human life span, that is, from 5 to $85+$ years of age, thereby overcoming the prevailing restriction on beliefs about adult development. In doing so, we aimed at a more encompassing picture of people's normative representations of life span development. Second, we compared beliefs about typical development held by children, adolescents, younger adults, and older adults, again overcoming the predominant emphasis on adults. The purpose of this extension was to better understand the emergence of the previously observed consensus in subjective beliefs about normal development. Third, we investigated potential age-related differences in the accuracy (or validity) of beliefs about normal development, that is, the match of these beliefs to prevailing theoretical assumptions and available empirical evidence. To our knowledge, the accuracy of subjective beliefs about typical development has not yet been addressed in a quantitative fashion. By exploring the degree of correspondence between beliefs and performance trajectories, we aimed at disentangling whether these differences reflect a bias in older age groups regarding the magnitude of developmental decline during adulthood, which could potentially serve purposes of self-enhancement, or more accurate (realistic) assumptions of older adults about typical development, which could derive from their accumulated personal experience and enhanced exposure to other people's developmental change.

\section{Acquisition of Beliefs About Typical Life Span Development}

A fundamental requirement for the formation of normative representations of life span development is temporal coherence, that is, the ability to order events, experiences, thoughts, or observations chronologically. Without this ability, beliefs about life span development cannot be adequately represented. Basic aspects of temporal coherence are acquired during the preschool years, but the ability to solve more complex temporal-sequencing tasks spanning larger periods of time only emerges during late middle childhood, at around the age of 9 years (Friedman \& Lyon, 2005; Habermas \& Bluck, 2000).
Once temporal coherence is acquired, two sources of information appear particularly relevant for the formation of beliefs about normal development-on the one hand, culturally shared and transmitted scripts about normative development, and on the other hand, personal experiences of one's own and others' developmental change. Cultural scripts about normative biographical and developmental change provide a scaffold, or frame of reference, for the individual's own development, and serve to structure perceptions of, and inferences about, other persons as a function of their age. Such normative scripts about development are transmitted within cultures and learned relatively independently from one's own personal experiences and observations (Habermas, 2007). Cultural scripts about normative development have mostly been studied with regard to representations of the normative sequence and timing of life events, such as undergoing professional training or having children. Evidence suggests that children learn these cultural scripts gradually during the transition period from late childhood to early adolescence, and have typically acquired them at about the age of 13 (Bohn \& Berntsen, 2008; Habermas, 2007). It seems plausible to assume that cultural knowledge about typical life span trajectories of specific aspects of functioning (e.g., developmental growth, stability, and decline of particular skills) is acquired at about the same time. The few studies that investigated such beliefs in adolescents have indeed found relatively high similarity to the beliefs held by adults (Heckhausen, 1999; Schorsch, 1992). Individuals who have acquired cultural scripts about normative development (i.e., from about 13 years of age on) should differ from younger individuals who have not yet acquired them in their average assumptions about the characteristics of the life span trajectory of a given domain of functioning. They should also be less variable in these life span assumptions, that is, they should show a relatively high degree of consensus. Assuming that cultural scripts are valid reflections of typical development in a given cultural context, individuals who have acquired cultural scripts should thus have a comparatively more accurate understanding of the typical life span trajectory of a given ability or domain of functioning (i.e., their representations of development should correspond more closely to empirically observed average patterns of development in a given domain of functioning). Cultural scripts are an integral part of an individual's world knowledge, and hence, once acquired, should be maintained well into old age.

In addition to cultural scripts, we assume that individuals' own developmental experiences and evaluations of the development of other people represent a second source of information contributing to beliefs about typical development. The ability to assess one's own and others' competencies and characteristics has been found to develop steeply as children transition from kindergarten to elementary school. This derives from children's cognitive advancement and their increasing exposure to a broad range of activities and tasks, as well as from the increasing amount of competence-related feedback they receive that is based on objective success criteria and interindividual comparisons as evaluation standards (e.g., Cole et al., 2001; Stipek \& Iver, 1989). Thus, children in middle elementary school should be able to form and report beliefs about development, even though they may not yet have fully internalized the respective cultural scripts. In addition, with advancing age and after having internalized normative cultural scripts, accumulated exposure to developmental change in 
oneself and others might further shape one's beliefs about typical development. On the one hand, one could assume that life experience may contribute to a further increase in the accuracy of beliefs about typical development (cf. Heckhausen et al., 1989). On the other hand, it is also possible that an age-related increase in the projection of one's own experiences and self-views onto one's beliefs about typical development might decrease the accuracy of the latter (externalization effect; cf. Rothermund \& Brandtstädter, 2003).

In addition to information provided by cultural scripts and personal experiences, motivational factors might also influence beliefs about typical development. Self-worth protective tendencies, for example, might facilitate particularly positive beliefs about the typical performance levels of one's own age group, especially when one thinks that one's own performance is at least as good as that of one's typical age peer. In fact, there is evidence that older adults tend to evaluate their own level of functioning more positively than that of typical older adults (Kornadt \& Rothermund, 2011; Rothermund \& Brandtstädter, 2003), and it has been speculated that older adults' comparatively optimistic beliefs about adult development might actually reflect not a higher, but rather a lower, accuracy of beliefs about typical development due to self-worth protective biases (e.g., Lineweaver \& Hertzog, 1998). The present study set out to test these possibilities against one another.

\section{Investigating the Accuracy of Beliefs About Typical Development}

An important goal of the present study was to explore age group differences in the accuracy of beliefs about typical development. To meet this aim, we asked children, adolescents, younger adults, and older adults to characterize how various aspects of cognitive and social functioning develop across the life span. We specifically aimed at including those aspects of functioning for which clear theoretical assumptions and converging empirical evidence regarding typical developmental trajectories are available. The probably most extensively researched domain in this respect to date is cognitive functioning. There is ample evidence that two broad classes of developmental trajectories of cognitive abilities can be distinguished (Baltes, Lindenberger, \& Staudinger, 1998; Cattell, 1943; Li et al., 2004). Fluid abilities assess individual differences in the speed, accuracy, and coordination of basic informationprocessing operations_-or the "mechanics" (Baltes, 1987) of cognition. Empirical evidence demonstrates a pattern of rapid growth during infancy and childhood into adolescence, followed by a monotonic and roughly linear decline during adulthood, and a further acceleration of decline in very old age. Crystallized abilities (Cattell, 1971; Horn, 1989) comprise the culturally transmitted bodies of knowledge individuals acquire in the course of their socialization-or the "pragmatics" (e.g., Baltes, 1987) of cognition. Plenty of evidence suggests that this knowledge base remains stable or increases well into young-old age, and only after that shows some decline, the acceleration of which is much less pronounced than the decline in fluid cognitive abilities. We also included aspects of social functioning, even though the available evidence on typical life span changes is less comprehensive and conclusive. There is, however, a strong theoretical note in current life span psychology that social functioning may be among the developmental domains that are maintained well into old age (e.g., Charles \& Carstensen, 2010), and that this is the case despite an age-related decline in social network size. Empirical evidence demonstrates that the age-related reduction in social network size mainly results from older adults' having fewer network members to whom they do not feel very close, whereas the network size of emotionally close social partners remains stable throughout adulthood (see a meta-analysis by Wrzus, Hänel, Wagner, \& Neyer, 2013), and that older adults typically report more positive social experiences, fewer social conflicts, and higher levels of satisfaction with their social relationships than younger individuals do (see review by Luong, Charles, \& Fingerman, 2011).

We took two approaches to evaluate the validity of beliefs that children, adolescents, younger adults, and older adults hold about typical human development. First, we investigated whether the developmental trajectories suggested by current developmental theories and empirical evidence (e.g., earlier and steeper decline in fluid compared with crystallized aspects of cognition) are reflected in participants' beliefs about typical development, and whether there are age-related differences in this respect. Second, we used biexponential latent growth curve models to analyze beliefs about life span development of selected aspects of functioning (cf. Cerella \& Hale, 1994). These analyses allow characterizing the developmental growth, peak, and decline assumptions for given facets of functioning in the four investigated age groups and permit comparing them with existing data about age gradients in actual (i.e., empirically observed) performance. Results from a largescale longitudinal investigation provided the standard of reference for these comparisons (McArdle, Ferrer-Caja, Hamagami, \& Woodcock, 2002). More detailed information on this investigation is provided in the Method section.

\section{Summary of Hypotheses}

Based on these conceptual considerations, we derived the following predictions.

Hypothesis 1: Nine-year-old children (whom we expect to have not yet acquired cultural scripts on normative development) should differ from adolescents, younger adults, and older adults (whom we expect to have acquired cultural scripts) in their average beliefs about performance levels of a given aspect of functioning in different phases of the life span. Differences among the latter three age groups should be comparatively smaller.

Hypothesis 2: Consensus in representations of life span development should be higher among adolescents, younger adults, and older adults than among children.

Hypothesis 3: Adolescents, younger adults, and older adults should have representations of life span development that closely correspond to empirical evidence of typical life span development, and to contemporary development theories. In contrast, children's conceptions should correspond less well to performance data and theory. Specifically, adolescents, younger adults, and older adults should represent fluid abilities as reaching their developmental peak earlier in life and as declining more steeply in later periods than crystallized abilities, whereas such a differentiated representation may not yet 
be evident in 9-year-old children (Hypothesis 3a). Furthermore, assumptions that adolescents and younger and older adults hold about the developmental growth, peak, and decline of fluid and crystallized abilities should correspond to empirically observed life span trajectories of actual performance. Such correspondence may not yet be evident in 9-year-old children (Hypothesis 3b).

Hypothesis 4: Despite considerable consensus among adolescents, younger adults, and older adults, beliefs about typical development should be most favorable among older adults. An increase in the accuracy of these beliefs from adolescence to old age would support the notion that older adults have more refined representations of normal development. In contrast, a decrease in the accuracy of these beliefs from adolescence to old age would support the possibility of biases in older adults' beliefs about development. Co-occurrence with older individuals' self-assessments as being equivalent, or better, than their average age peers would support the possibility of selfenhancing functions for such biases.

\section{Method}

\section{Sample}

The effective sample consisted of thirty-six 9-year-olds $(M=$ 9.4 years, $S D=.26)$, forty 13 - to 15 -year olds $(M=14.1$ years, $S D=0.6)$, forty 21 - to 26 -year olds $(M=23.4$ years, $S D=1.4)$, and forty 70 - to 76 -year olds $(M=72.7$ years, $S D=1.5)$. Forty children were tested, but data from four children were excluded from the analyses. Three children provided incomplete data for the questions on beliefs about normal development, and one child chose the same rating for all 100 responses, due either to a misunderstanding of task instructions or to an unwillingness to comply with them. The sample was stratified by sex, with almost equal numbers of males and females in each group (children $=20$ males, 16 females; adolescents $=21$ males, 19 females; younger adults $=20$ males, 20 females; older adults $=20$ males, 20 females). Participants were drawn from the participant pool of the Max Planck Institute for Human Development in Berlin. The majority of the children attended elementary school (97\%), and the majority of the adolescents attended extended secondary school (leading to German university-entrance qualification; $72.5 \%$ ). Eighty-two-and-a-half percent of the young adults and $52.5 \%$ of the older adults had the German university-entrance qualification (Abitur). In accordance with the developmental literature, young adults performed better than children and older adults in standard- ized tests assessing cognitive speed and reasoning, whereas older adults possessed more knowledge of vocabulary than the other three age groups (see Table 1). Data were collected in the context of a larger project on age differences in difficulty choices for cognitive challenges (for a description of the complete study procedure, see Schaefer, Riediger, Li, \& Lindenberger, 2013). None of the data reported here have been published before. Participants were tested in age-homogenous group sessions with up to five participants per group, and received monetary reimbursement for their participation ( $€ 10$ for the session that is relevant here). The institute's ethics committee approved the study.

\section{Assessing Beliefs About Normal Development}

Participants read the following instruction on the computer screen:

In the following, we are interested in your notions about how various abilities and domains change on average in other people throughout the course of their lives. The questions do not concern your personal development, but rather your beliefs about how people develop on average. Please indicate for each of the following domains how you believe it typically develops from childhood to old age.

After that, participants were sequentially presented with the following cognitive and social aspects of functioning: (a) mental arithmetic; (b) ability to memorize; (c) general education/knowledge; (d) cognitive speed; (e) cognitive accuracy; (f) ability to concentrate/attention; $(\mathrm{g})$ harmonious contacts to close friends, family, or acquaintances; (h) ability to get to know new people; (i) ability to hold one's ground against others/to assert oneself; and (j) ability to solve conflicts. For each of these 10 aspects of functioning, participants indicated on a 10-point rating scale at which level an average person performs at 5, 10, 15, 20, 30, 40, 50, 60, 70, and $85+$ years of age. Participants indicated their responses on a lever operated via a special pen on a WACOM touch screen. Taken together, each participant provided 100 ratings (10 aspects of functioning evaluated at 10 different ages).

\section{Self-Evaluation of Current Functioning}

Participants evaluated their own current level of functioning for each of the 10 domains with the same 10-point rating scale used in the assessment of beliefs about development. Beliefs about typical development and self-evaluations of current functioning were assessed in separate sessions.

Table 1

Sample Description: Cognitive Functioning

\begin{tabular}{|c|c|c|c|c|c|c|c|c|c|}
\hline \multirow[b]{2}{*}{ Construct } & \multirow[b]{2}{*}{ Measure } & \multicolumn{2}{|c|}{ Children } & \multicolumn{2}{|c|}{ Adolescents } & \multicolumn{2}{|c|}{ Younger adults } & \multicolumn{2}{|c|}{ Older adults } \\
\hline & & $M$ & $S D$ & $M$ & $S D$ & $M$ & $S D$ & $M$ & $S D$ \\
\hline Cognitive speed & Digit symbol $^{\mathrm{a}}$ & 33.2 & 5.8 & 50.6 & 10.1 & 58.5 & 9.5 & 42.8 & 10.1 \\
\hline Vocabulary & MWT-A $^{\mathrm{b}}$ & 13.8 & 2.9 & 24.9 & 4.2 & 30.6 & 3.5 & 32.8 & 2.5 \\
\hline Reasoning & Figural Analogies Test ${ }^{\mathrm{c}}$ & 12.1 & 4.4 & 13.7 & 4.2 & 16.6 & 3.2 & 10.0 & 4.6 \\
\hline
\end{tabular}

${ }^{\mathrm{a}}$ Digit Symbol Substitution Test of the Wechsler Intelligence Scales (Wechsler, 1981). ${ }^{\mathrm{b}}$ Mehrfachwahl-Wortschatz-Intelligenztest (Multiple-Choice Vocabulary Intelligence Test; Lehrl, Merz, Burkhard, \& Fischer, 1991). ${ }^{\mathrm{c}}$ Figural Analogies Test (Thorndike, Hagen, \& Lorge, 1954). 


\section{Empirical Reference Standards for Evaluating the Accuracy of Beliefs About Normal Development}

We evaluated the accuracy of participants' beliefs about typical development for the following selection of abilities: (a) ability to memorize, (b) cognitive speed, and (c) general education/knowledge. Results from a large-scale longitudinal study on age related changes in cognitive functioning (McArdle et al., 2002) provided the empirical standards of comparison. This comparison study analyzed data from 1,193 individuals ranging in age from 2 to 95 years, for whom at least two longitudinal assessments of the Woodcock-Johnson Psycho-Educational Battery - Revised (WJ-R; Woodcock \& Johnson, 1989) were available. The interval between assessments varied from less than one to 10 years $(M=2.7$ years; $\left.r_{\text {age }}=.10\right)$. The WJ-R includes, among other things, individually administered tests of several factors of intellectual abilities. The analyses that follow focused on short-term memory, processing speed, and comprehension knowledge.

\section{Results}

Figure 1 is a graphic representation of participants' beliefs about how the investigated cognitive aspects of functioning typically develop across the life span. Figure 2 is an analogous representation of participants' beliefs about how social aspects of functioning develop across the life span. It is evident in both figures that the beliefs about typical development held by 9 -year-old children deviated markedly from those reported by the other three age groups. These differences concern both the expected level of functioning and the form of the expected trajectory of developmental change throughout life. Another characteristic that is evident at first glance from Figures 1 and 2 is that, compared with the other age groups, older adults held more optimistic expectations about normative development in middle and old adulthood than did individuals in the other age groups.

To substantiate this first impression and to test our study predictions, we took three data-analytic approaches. First, we addressed differences in the average levels of functioning that participants from various age groups ascribed to various developmental phases across the life span. Second, we analyzed the variability of beliefs about normal development (i.e., the degree of consensus) within the four age groups, and whether there were age-related differences in this respect. Finally, we conducted biexponential latent growth curve analyses examining beliefs about the shape of typical life span trajectories for selected cognitive aspects of functioning and compared them with empirical reference values provided by McArdle and colleagues (2002). Results of these analyses are presented in the following sections.

\section{Beliefs About Typical Levels of Functioning in Different Phases of the Life Span}

Hypothesis 1 predicted that the beliefs held by 9-year-old children would differ from those of participants in the other age groups, and that the differences in beliefs among the three other age groups would be smaller. To investigate these predictions, we conducted multivariate analyses of variance (MANOVAs), using SPSS version 15.0. Age group of participants (i.e., children, ado- lescents, younger adults, older adults) was specified as the between-person factor, and evaluated age of functioning (i.e., 5, $10,15,20,30,40,50,60,70,85+$ years) as the within-person factor. Beliefs about typical levels of functioning served as dependent variables. Although the multivariate $F$ test in MANOVA accounts for variance heterogeneity over time (i.e., does not depend on the sphericity assumption of repeated measures ANOVA), it assumes variance homogeneity across the four age groups. As will be demonstrated in the following (and as postulated in Hypothesis 2), this assumption was violated for all 10 constructs (Box's $M$ tests of equality of covariance structures were significant at the $1 \%$ level). We therefore complemented our analyses by reformulating the MANOVA model as a structural equation model (SEM) and determining likelihood ratio based $p$ values that do not depend on the assumption of variance homogeneity across groups (see Voelkle, 2007, for details). These analyses were carried out using the lavaan package in R (Rosseel, 2012). Results are presented in Table 2. For most analyses, the main effects of age group of participants were significant. Exceptions emerged when variance heterogeneity was taken into account and involved the evaluations of cognitive accuracy and the abilities to concentrate/ attention, to solve conflicts, and to get to know new people. The main effects for the evaluated age of functioning were significant in all analyses, as were the respective interactions of Age Group of Participants $\times$ Evaluated Age of Functioning. Evidently, the four age groups differed in their age-based beliefs about all aspects of functioning examined in this study.

Helmert contrasts confirmed Hypothesis 1-that children's beliefs about normal development departed from those of the combined other age groups-for six of the 10 investigated domains of functioning (see Table 3). To further follow up on these age differences and to address Hypothesis 4, we conducted pairwise comparisons of beliefs about normal development reported by older participants (reference group) with the other three age groups of participants, separately for each of the evaluated ages. The results of these analyses are presented in Appendix A. Differences between older participants and participants from the other age groups were most pronounced for evaluations of functioning in the life phase from middle to young-old adulthood (i.e., 30 to 60 years of age), particularly for children and adolescents. Consistent with Hypothesis 4, the directions of these age differences clearly indicated more optimistic assumptions of normative levels of functioning during this life phase in older participants (see also Figures 1 and 2).

\section{Variance Within Age Groups in Beliefs About Normal Development}

Hypothesis 2 predicted that 9-year-old children should show comparatively lower consensus with their age peers in beliefs about normal development than adolescents, younger adults, and older adults. To investigate this prediction, we employed the same multigroup (age group of participants), SEM-based MANOVA approach used to study differences in beliefs about typical levels of functioning at different ages throughout the life span. In contrast to the previously described analyses in which we focused on mean differences, however, we now focus on the variation within each of the four age groups. For this purpose, we computed the total variance within each age group by taking the trace of the $10 \times 10$ 

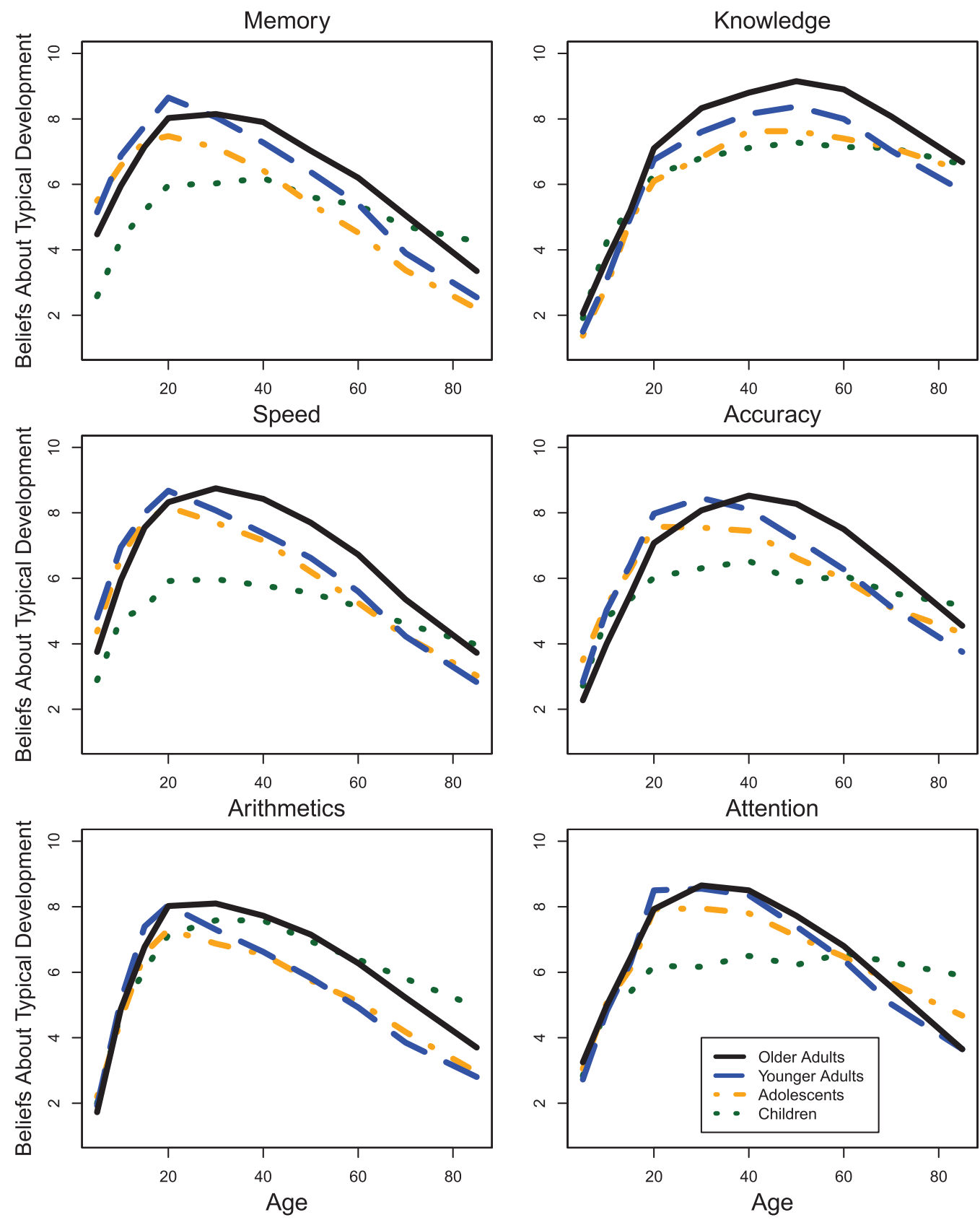

Figure 1. Beliefs about the typical development of investigated cognitive aspects of functioning. The color version of this figure appears in the online article only.

dimensional covariance matrix of the $T-1=9$ orthogonally transformed polynomial growth factors and the between-person factor. We interpret this as a measure of (lack of) consensus, because it reflects the degree of interindividual differences in perceived performance levels along with the interindividual differences in perceived changes in performance across the life span. If Hypothesis 2 were correct, we would expect children to exhibit higher total variance than any of the other three age groups. Figure 3 depicts the estimates of total variance obtained for each of the four age groups and all 10 domains of functioning.
Consistent with Hypothesis 2, 9-year-old children showed considerably higher total variance for all 10 aspects of functioning than any of the other three age groups. To statistically substantiate differences in total variance in beliefs about typical development between children and the other age groups, we compared the likelihood of a model in which all variances were constrained to equality across the four age groups with the likelihood of a model in which the variances of children were allowed to differ from those of adolescents, younger adults, and older adults. This constitutes a multivariate test of whether consensus (i.e., total vari- 

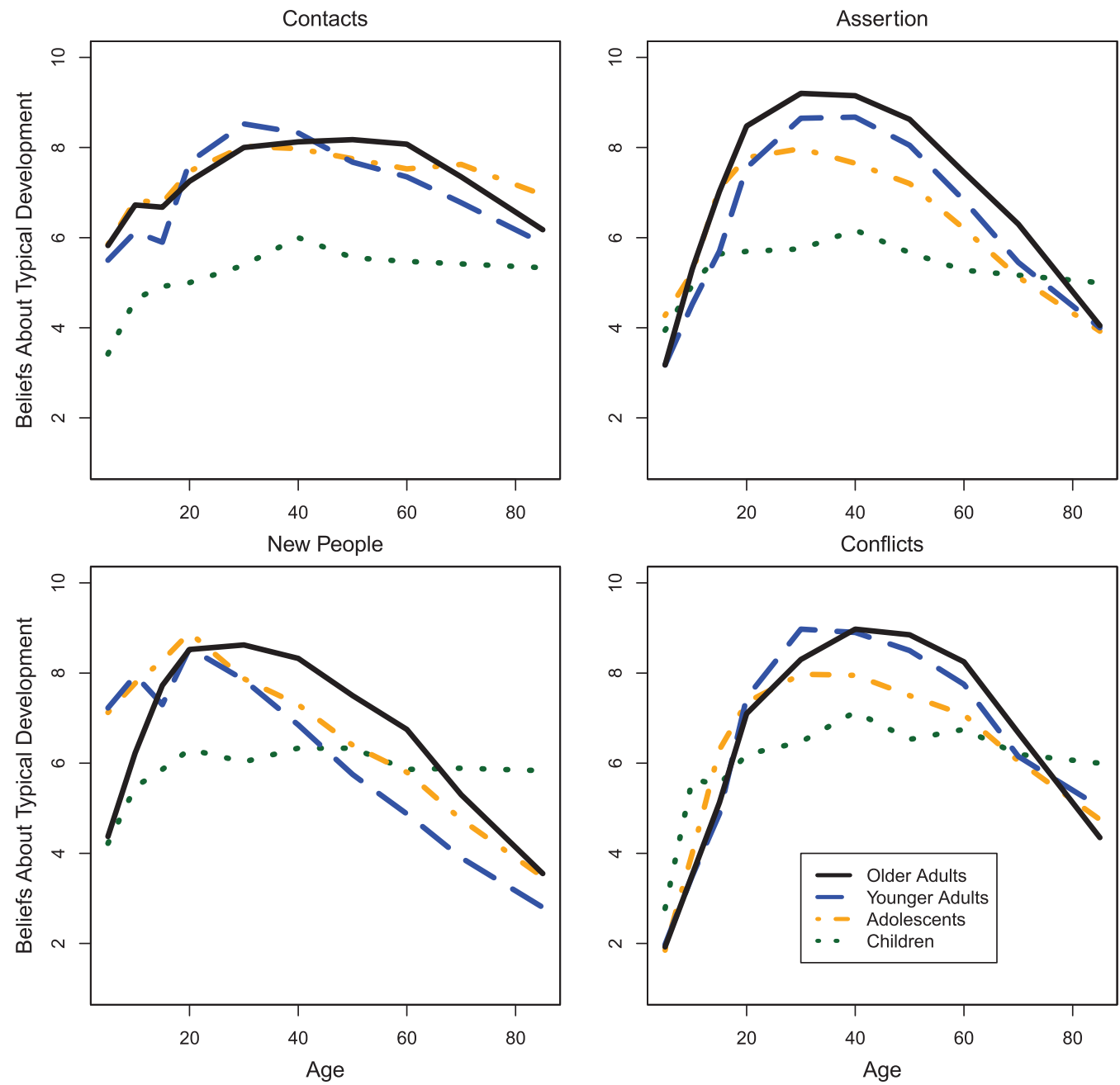

Figure 2. Beliefs about the typical development of investigated social aspects of functioning. The color version of this figure appears in the online article only.

ance) among the group of children is lower than among all other age groups. In fact, except for evaluations of cognitive accuracy, $\chi^{2}=15.944, d f=10, p=.101$, this was the case for all domains of functioning (memory: $\chi^{2}=35.723, p<.001$; knowledge: $\chi^{2}=$ 52.028, $p<.001$; speed: $\chi^{2}=64.725, p<.001$; calculation: $\chi^{2}=22.844, p<.05$; attention: $\chi^{2}=50.438, p<.001$; contacts: $\chi^{2}=38.995$, new friends: $\chi^{2}=37.605, p<.001$; conflict: $\chi^{2}=$ 57.787, $p<.001$; power: $\chi^{2}=43.496, p<.001$; all $d f_{\mathrm{s}}=10$ ).

\section{Validity of Expected Developmental Trajectories for Selected Aspects of Functioning}

We investigated potential age differences in the validity of beliefs about typical development for three selected aspects of functioning, namely, the ability to memorize, cognitive speed, and general education/knowledge. We chose these aspects because converging empirical evidence and theoretical assumptions about their life span development were available as validity criteria. Biexponential latent growth curve analyses, conducted in Mplus version 6.1 (Muthén \& Muthén, 1998-2011), provided the statis- tical basis for these validity explorations. We proceeded from the following base model:

$$
y_{i t}=b_{0 i}+b_{1 i} \cdot \mathrm{e}^{b_{3} \cdot a g e}-b_{2 i} \cdot \mathrm{e}^{b_{4} \cdot a g e}+\varepsilon_{i t},
$$

with $y_{i t}$ denoting the belief of individual $i=1 \ldots N$ about the ability to memorize, cognitive speed, and general education/ knowledge, respectively, of a typical person at the evaluated age $($ age $)=5,10,15,20,30,40,50,60,70,85+$ years (i.e., at time point $t=1 \ldots T=10)$. Note that this model is a combination of an exponential increase $\left(b_{1 i} \cdot \mathrm{e}^{b_{3} \cdot a g e}\right)$ and decline $\left(-b_{2 i} \cdot \mathrm{e}^{b_{4} \cdot a g e}\right)$ part, and has been previously used to analyze information processing rates over the life span (e.g., Cerella \& Hale, 1994; Li et al., 2004; McArdle et al., 2002). In particular, McArdle et al. (2002) employed a very similar model to study the growth and decline of multiple intellectual abilities over the life span, which allows us to compare our results with theirs to test the validity of beliefs about typical life span changes. In addition to the growth and decline part, the model contains a random intercept $\left(b_{0 i}\right)$ and an error term $\varepsilon_{i t}$ specific to person $i$ and time point $t$. In contrast to McArdle et 
Table 2

Summary of Results From Repeated-Measures MANOVAs on Subjective Beliefs About Development

\begin{tabular}{|c|c|c|c|c|c|c|c|c|c|c|c|c|}
\hline & \multicolumn{4}{|c|}{ Age group of participants } & \multicolumn{4}{|c|}{ Evaluated age of functioning } & \multicolumn{4}{|c|}{ Age of participants $\times$ evaluated age } \\
\hline & $F^{\mathrm{a}}$ & $p$ & $p^{\mathrm{b}}$ & Part. $\eta^{2}$ & $F^{\mathrm{c}, \mathrm{d}}$ & $p$ & $p^{\mathrm{b}}$ & Part. $\eta^{2}$ & $F^{\mathrm{c}, \mathrm{e}}$ & $p$ & $p^{\mathrm{b}}$ & Part. $\eta^{2}$ \\
\hline Memory & 5.602 & .001 & .003 & .100 & 65.114 & .000 & .000 & .803 & 3.941 & .000 & .000 & .197 \\
\hline Knowledge & 3.368 & .020 & .000 & .062 & 183.715 & .000 & .000 & .920 & 3.770 & .000 & .000 & .190 \\
\hline Speed & 10.502 & .000 & .000 & .172 & 82.142 & .000 & .000 & .837 & 3.553 & .000 & .000 & .181 \\
\hline Accuracy & 1.845 & .141 & .259 & .035 & 74.839 & .000 & .000 & .824 & 3.799 & .000 & .000 & .191 \\
\hline Mental arithmetic & 3.262 & .023 & .015 & .060 & 122.547 & .000 & .000 & .885 & 1.957 & .003 & .002 & .109 \\
\hline Attention & 1.176 & .321 & .524 & .023 & 75.330 & .000 & .000 & .825 & 4.953 & .000 & .000 & .235 \\
\hline Harmonious contacts & 12.391 & .000 & .000 & 197 & 20.631 & .000 & .000 & .563 & 3.434 & .000 & .000 & .176 \\
\hline Assertion & 6.185 & .001 & .001 & 109 & 63.457 & .000 & .000 & .799 & 4.775 & .000 & .000 & .229 \\
\hline New people & 2.702 & .048 & .093 & .051 & 59.499 & .000 & .000 & .788 & 7.377 & .000 & .000 & .314 \\
\hline Solve conflicts & .734 & .534 & .561 & $.014^{\mathrm{f}}$ & 123.636 & .000 & .000 & .885 & 6.178 & .000 & .000 & .277 \\
\hline
\end{tabular}

${ }^{\mathrm{a}} d f_{\text {numerator }}=3, d f_{\text {denominator }}=152 .{ }^{\mathrm{b}} \mathrm{p}$ value based on likelihood ratio test accounting for heterogeneity of covariance structures across age groups. $\quad{ }^{\mathrm{c}}$ Multivariate $F$ test based on Wilks' $\lambda . \quad{ }^{\mathrm{d}} d f_{\text {numerator }}=9, d f_{\text {denominator }}=144 . \quad{ }^{\mathrm{e}} d f_{\text {numerator }}=27, d f_{\text {denominator }}=421.197 . \quad{ }^{\mathrm{f}}$ Unbiased effect size estimate is zero.

al., we allowed $b_{1 i}$ and $b_{2 i}$ to both be freely estimated and to vary across individuals. In line with McArdle et al., $b_{3}$ and $b_{4}$ were freely estimated, but constrained to equality across individuals.

To investigate possible age-related differences, we further included age group (dummy coded with children as reference group) as predictors of $b_{0 i}, b_{1 i}$, and $b_{2 i}$, as shown in Equation 2:

$$
\begin{aligned}
b_{0 i}= & b_{0 \text { Children }}+b_{0 \text { Adolescents }} \cdot D_{1}+b_{0 \text { YoungerAdults }} \cdot D_{2} \\
& +b_{0 \text { olderAdults }} \cdot D_{3}+\zeta_{0 i} \\
b_{1 i}= & b_{1 \text { Children }}+b_{1 \text { Adolescents }} \cdot D_{1}+b_{1 \text { YoungerAdults }} \cdot D_{2} \\
& +b_{1 \text { OlderAdults }} \cdot D_{3}+\zeta_{1 i} \\
b_{2 i}= & b_{2 \text { Children }}+b_{2 \text { Adolescents }} \cdot D_{1}+b_{2 \text { YoungerAdults }} \cdot D_{2} \\
& +b_{2 \text { olderAdults }} \cdot D_{3}+\zeta_{2 i}
\end{aligned}
$$

Results of these analyses are presented in Appendices B through D. Proceeding from these parameter estimates, we derived the expected age of maximum performance (age at peak), the expected age of maximal developmental decline (age at deceleration), the expected performance levels at peak and deceleration (scores at peak/deceleration), and the expected performance changes between ages 2 and 19 and between ages 20 and 75 for each of the four investigated participant age groups. The choice of these

Table 3

Helmert Contrasts of Beliefs About Typical Levels of Functioning: Children Versus All Other Age Groups

\begin{tabular}{lrrr}
\hline & Contrast & $S E$ & $p$ \\
\hline Memory & -1.017 & .297 & .001 \\
Knowledge & -.269 & .279 & .336 \\
Speed & -1.361 & .258 & .000 \\
Accuracy & -.650 & .292 & .027 \\
Mental arithmetic & .407 & .251 & .106 \\
Attention & -.522 & .292 & .076 \\
Harmonious contacts & -2.049 & .339 & .000 \\
Assertion & -1.135 & .299 & .000 \\
New people & -.774 & .309 & .013 \\
Solve conflicts & -.310 & .258 & .231 \\
\hline
\end{tabular}

characteristics and the way they were derived follows McArdle et al. (2002).

Table 4 summarizes the means and their $95 \%$ confidence intervals for each of these trajectory characteristics in the four investigated age groups. It also includes the reference values obtained in the empirical investigation by McArdle and colleagues (2002). To allow comparisons between developmental beliefs (the present study) and empirical observations of development (McArdle et al., 2002), scale scores obtained in the latter study were transformed to the scale metric used in the present investigation. Figure 4 graphically depicts the model-predicted beliefs about typical developmental trajectories for each of the four participant age groups, as well as the expected ages at maximum performance and maximal developmental decline.

Inspection of Table 4 reveals overlapping 95\% confidence intervals for all characteristics of the developmental trajectories expected by adolescents, younger adults, and older adults, which further provides evidence for the hypothesized consensus of developmental beliefs in these age groups. This pattern also provides a notable refinement of our findings regarding Hypothesis 4, which predicted that older adults would hold the most favorable beliefs about normal development. We have already reported that older participants indeed tended to expect comparatively higher levels of functioning in middle and older adulthood than the other age groups did. The results in Table 4 show that these more favorable expectations of life span development did not, however, concern beliefs about the shape of expected developmental trajectories, which were highly consensual among adolescents, younger adults, and older adults.

Occurrences of nonoverlapping 95\% confidence intervals for characteristics of expected developmental trajectories involve comparisons with the developmental beliefs held by children. This supports the assumption of relative discordance of beliefs about typical development in 9-year-old children compared with those in the other age groups (Hypothesis 1). It is interesting, however, that the majority of these discrepancies concerned beliefs about the development of the two fluid abilities (i.e., the ability to memorize and cognitive speed), whereas children's beliefs about developmental trajectories for crystallized abilities (i.e., general education/ knowledge) were more in accordance with those of the other age 


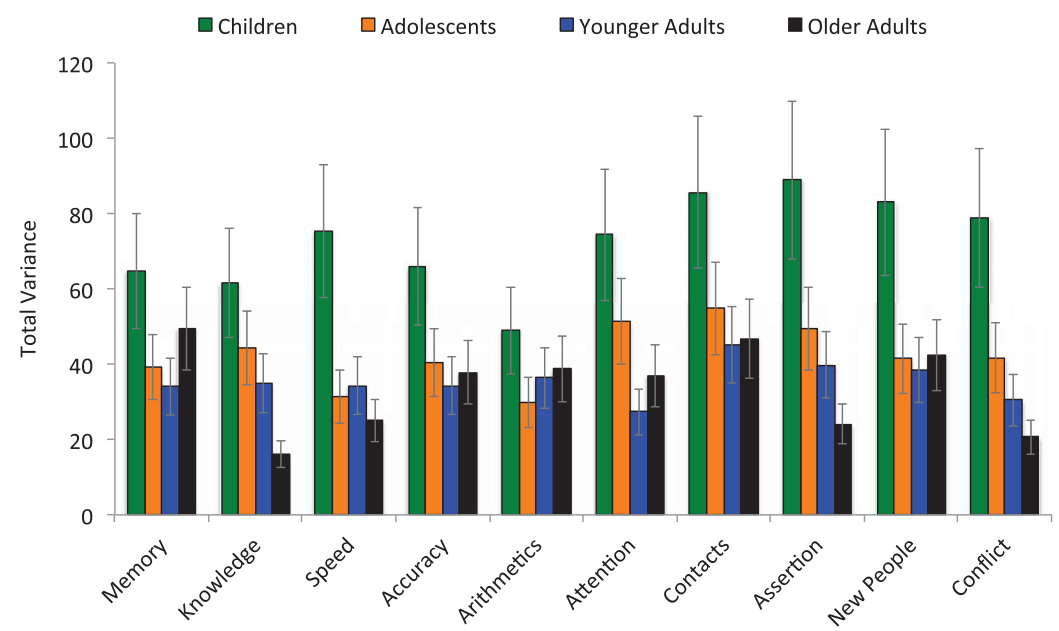

Figure 3. Age group differences in estimated between-person (intercept) variance in beliefs about typical development. Error bars represent $\pm 1 S E$. The color version of this figure appears in the online article only.

groups. According to Hypothesis 3a, the relative validity of beliefs about normal development in adolescents, younger adults, and older adults would be evident in expectations of differential developmental trajectories for fluid versus crystallized cognitive abilities. Comparison of the $95 \%$ confidence intervals of the expected age of peak performance, expected age of maximal developmental decline, and developmental change between ages 20 and
75 across the different aspects of functioning indeed revealed that these three age groups believed that memory abilities and cognitive speed would reach their developmental peaks earlier in life, and that they would decline more steeply than general education/ knowledge. It is interesting that the same pattern of differential beliefs about normal development was already evident in 9-yearold children. Thus, individuals of all investigated age groups held

Table 4

Model-Predicted Characteristics of Developmental Trajectories Believed to Be Normative for Three Aspects of Cognitive Functioning by Participants of Various Age Groups, and Comparison With Reference Values Reported by McArdle et al. (2002)

\begin{tabular}{|c|c|c|c|c|c|c|c|c|c|c|c|c|c|}
\hline \multirow[b]{3}{*}{ Characteristic } & \multicolumn{3}{|c|}{ Children } & \multicolumn{3}{|c|}{ Adolescents } & \multicolumn{3}{|c|}{ Younger adults } & \multicolumn{3}{|c|}{ Older adults } & \multirow[b]{3}{*}{ Ref } \\
\hline & \multirow[b]{2}{*}{$M$} & \multicolumn{2}{|c|}{$95 \% \mathrm{CI}$} & \multirow[b]{2}{*}{$M$} & \multicolumn{2}{|c|}{$95 \%$ CI } & \multirow[b]{2}{*}{$M$} & \multicolumn{2}{|c|}{$95 \%$ CI } & \multirow[b]{2}{*}{$M$} & \multicolumn{2}{|c|}{$95 \% \mathrm{CI}$} & \\
\hline & & Lower & Upper & & Lower & Upper & & Lower & Upper & & Lower & Upper & \\
\hline \multicolumn{14}{|l|}{ Ability to memorize } \\
\hline Age at peak & 32.218 & 29.104 & 35.332 & 21.450 & 18.761 & 24.139 & 23.903 & 21.972 & 25.833 & 27.251 & 25.385 & 29.117 & 24.2 \\
\hline Age at deceleration & 62.862 & 58.334 & 67.390 & 52.094 & 47.870 & 56.318 & 54.547 & 50.719 & 58.375 & 57.896 & 54.109 & 61.683 & 48.4 \\
\hline Score at peak & 6.244 & 5.574 & 6.914 & 7.475 & 6.867 & 8.082 & 8.418 & 7.797 & 9.039 & 8.307 & 7.674 & 8.940 & $6.418^{\mathrm{a}}$ \\
\hline Score at deceleration & 5.157 & 4.606 & 5.708 & 5.210 & 4.663 & 5.757 & 5.802 & 5.222 & 6.382 & 6.136 & 5.571 & 6.700 & $5.734^{\mathrm{a}}$ \\
\hline Rate of $\Delta$ Ages 2-19 & 0.247 & 0.174 & 0.320 & 0.176 & 0.107 & 0.245 & 0.270 & 0.199 & 0.341 & 0.315 & 0.244 & 0.386 & $0.423^{\mathrm{a}}$ \\
\hline Rate of $\Delta$ Ages $20-75$ & -0.022 & -0.034 & -0.010 & -0.081 & -0.093 & -0.069 & -0.087 & -0.099 & -0.075 & -0.063 & -0.075 & -0.051 & $-0.028^{\mathrm{a}}$ \\
\hline \multicolumn{14}{|l|}{ Cognitive speed } \\
\hline Age at peak & 29.933 & 26.546 & 33.320 & 24.394 & 22.569 & 26.219 & 24.063 & 22.334 & 25.792 & 27.915 & 26.278 & 29.552 & 25.1 \\
\hline Age at deceleration & 57.629 & 53.344 & 61.914 & 52.091 & 48.867 & 55.315 & 51.759 & 48.596 & 54.922 & 55.611 & 52.520 & 58.702 & 50.2 \\
\hline Score at peak & 6.089 & 5.499 & 6.679 & 8.151 & 7.592 & 8.710 & 8.575 & 8.016 & 9.134 & 8.908 & 8.345 & 9.471 & $7.134^{\mathrm{a}}$ \\
\hline Score at deceleration & 5.157 & 4.675 & 5.639 & 6.024 & 5.540 & 6.508 & 6.271 & 5.779 & 6.763 & 6.830 & 6.334 & 7.326 & $5.911^{\mathrm{a}}$ \\
\hline Rate of $\Delta$ Ages $2-19$ & 0.222 & 0.153 & 0.291 & 0.293 & 0.228 & 0.358 & 0.306 & 0.241 & 0.371 & 0.411 & 0.344 & 0.478 & $0.535^{\mathrm{a}}$ \\
\hline Rate of $\Delta$ Ages 20-75 & -0.025 & -0.039 & -0.011 & -0.078 & -0.092 & -0.064 & -0.085 & -0.099 & -0.071 & -0.065 & -0.079 & -0.051 & $-0.052^{\mathrm{a}}$ \\
\hline \multicolumn{14}{|l|}{ General education/knowledge } \\
\hline Age at peak & 47.291 & 40.600 & 53.982 & 47.065 & 42.114 & 52.016 & 42.844 & 39.743 & 45.945 & 44.634 & 41.122 & 48.146 & 35.6 \\
\hline Age at deceleration & 90.756 & 76.178 & 105.34 & 90.529 & 76.754 & 104.30 & 86.308 & 73.143 & 99.473 & 88.098 & 74.892 & 101.31 & 71.3 \\
\hline Score at peak & 7.487 & 6.860 & 8.114 & 7.728 & 7.132 & 8.323 & 8.330 & 7.726 & 8.934 & 9.021 & 8.421 & 9.621 & $6.593^{\mathrm{a}}$ \\
\hline Score at deceleration & 6.167 & 5.254 & 7.080 & 6.040 & 5.044 & 7.036 & 5.818 & 4.558 & 7.078 & 6.736 & 5.542 & 7.930 & $5.950^{\mathrm{a}}$ \\
\hline Rate of $\Delta$ Ages 2-19 & 0.257 & 0.216 & 0.298 & 0.325 & 0.286 & 0.364 & 0.384 & 0.345 & 0.423 & 0.386 & 0.347 & 0.425 & $0.498^{\mathrm{a}}$ \\
\hline Rate of $\Delta$ Ages $20-75$ & 0.017 & 0.001 & 0.033 & 0.021 & 0.007 & 0.035 & 0.007 & -0.007 & 0.021 & 0.015 & 0.001 & 0.029 & $-0.004^{\mathrm{a}}$ \\
\hline
\end{tabular}

Note. Estimates derived from biexponential growth curve models (see Equations 1 and 2 and Appendices B, C, and D). Bold font indicates that the reference value observed by McArdle et al. (2002) is included in the $95 \%$ CI (with an accuracy of two positions after the decimal point). CI $=$ confidence interval; Ref $=$ reference values obtained from McArdle et al.

${ }^{\text {a }}$ Transformed to same scale metric as used in the present data collection. 

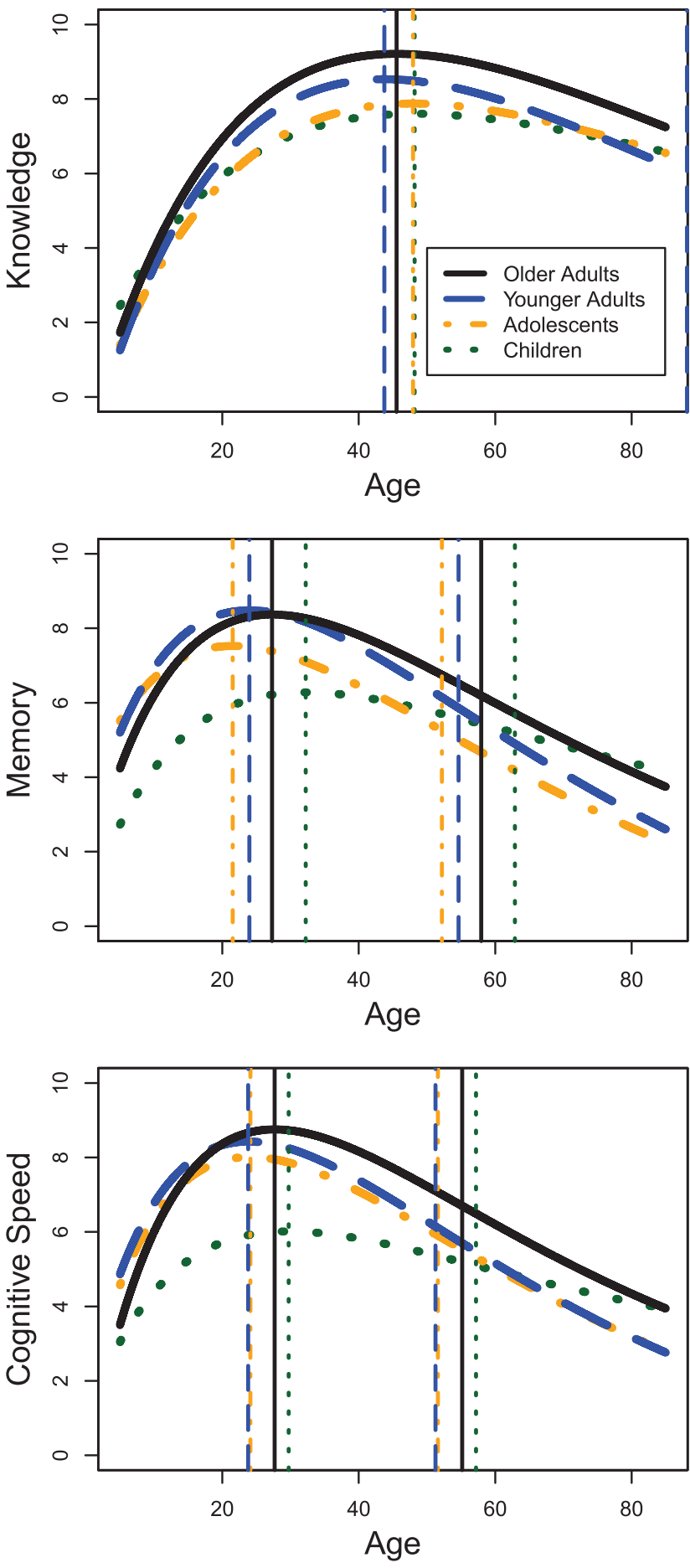

Figure 4. Model-predicted beliefs about developmental trajectories with expected age of peak performance and age of maximal performance decline. Expected age of maximal performance decline for knowledge is outside the depicted age range. The color version of this figure appears in the online article only. beliefs about differential life span trajectories of various cognitive abilities that are in agreement with empirical data, and with the life span theory of fluid versus crystallized intelligence (Cattell, 1971; Horn, 1989).

According to Hypothesis $3 \mathrm{~b}$, the beliefs held by adolescents, younger adults, and older adults would show relatively similar degrees of correspondence to empirical reference values of actual developmental change. In partial support of this prediction, the reference values established by McArdle and colleagues (2002) fell inside the $95 \%$ confidence intervals of the age gradients provided by adolescents and younger adults more often than in those provided by children and older adult participants. The latter finding speaks against an increase in the accuracy of beliefs about typical development in the transition from early to late adulthood, but is rather in line with the alternative interpretation that older adults' expectations of higher levels of functioning in middle and old adulthood may reflect positive biases.

\section{Differences Between Evaluations of Own Functioning and That of Typical Age Peers}

It has been argued that positive biases in older adults' beliefs about typical adult development may serve self-enhancing purposes (e.g., Lineweaver \& Hertzog, 1998). Such a self-enhancing function, however, can only be fulfilled when older adults evaluate their own performance level favorably relative to how they perceive their typical age peer. To explore this possibility, we determined, separately for each domain of functioning, the difference between participants' self-evaluation of their own current level of functioning and their belief about the typical performance level of their (approximate) age peers. For children, we used developmental beliefs for 10 years of age; for adolescents, developmental beliefs for 15 years; for younger adults, developmental beliefs for 20 years; and for older adults, developmental beliefs for 70 years of age as comparison values. Figure 5 depicts the average differences between self-evaluation of current functioning and expected level of functioning in typical age peers. The figure shows that older participants indeed evaluated their own current level of functioning as higher than that of their typical age peers for most of the investigated domains of functioning. A similar, but slightly less pronounced, pattern of positive differences is evident in children as well. In contrast, young adults and, to a lesser extent, adolescents evaluated their current performance level as lower than that of their typical age peer for several domains of functioning.

To statistically substantiate these apparent age-group differences, we performed a MANOVA on these difference scores with age group of participants as the between-person factor and domain of functioning as the within-person factor, using SPSS version 15.0. We again complemented our analyses by determining likelihood-ratio based $p$ values that do not depend on the assumption of variance homogeneity across groups. These analyses yielded significant main effects for age group of participants $\left(F[3]=10.669, p<.001\right.$, partial $\eta^{2}=.174$; likelihood-ratio $p<$ $.001)$ and for domain of functioning $(F[9,144]=2.019, p=.041$, according to Wilks' $\lambda$, partial $\eta^{2}=.112$; likelihood-ratio $p<$ $.001)$, as well as a significant interaction effect $(F[27,421.197]=$ $4.675, p<.001$, according to Wilks' $\lambda$, partial $\eta^{2}=.225$ likelihood-ratio $p<.001$ ). 


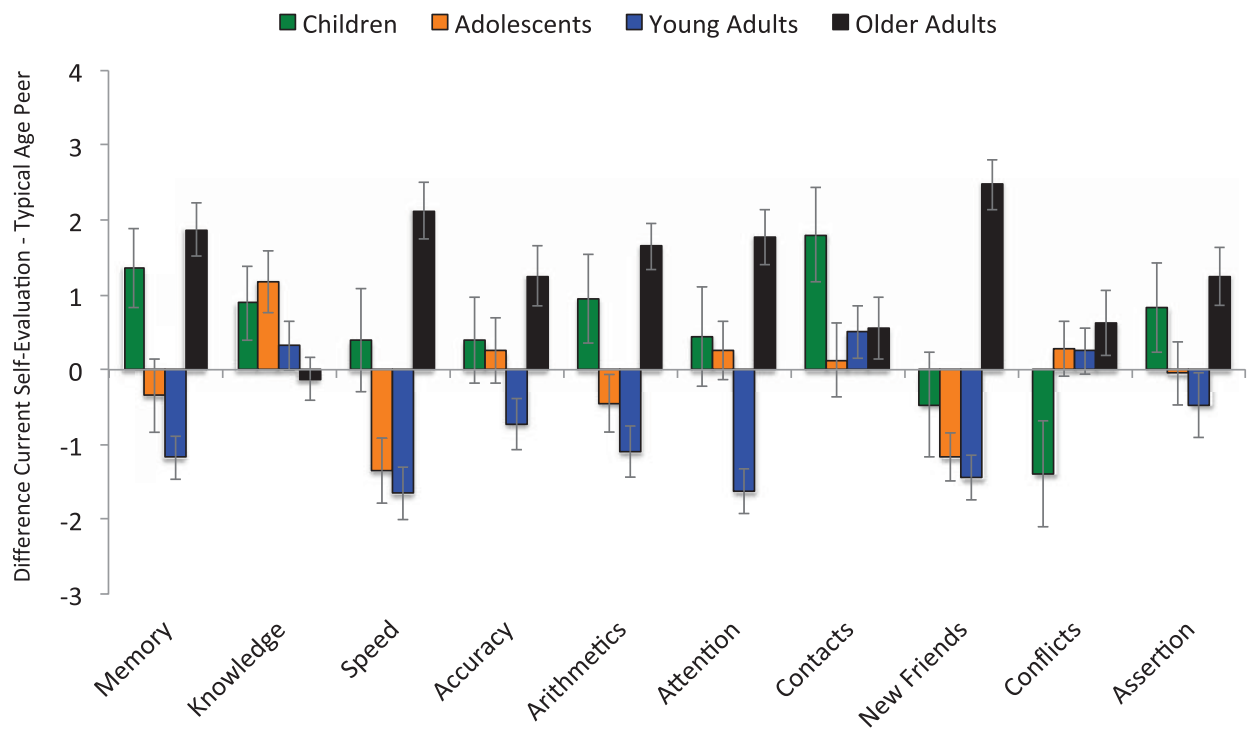

Figure 5. Differences between self-evaluations of own current functioning and evaluations of functioning in typical age peer. Error bars represent $\pm 1 S E$. The color version of this figure appears in the online article only.

Follow-up analyses showed significant univariate age effects for seven of the 10 investigated domains of functioning $(p<.05)$. The exceptions involved general education/knowledge, and the abilities to solve conflicts and to have harmonious contacts. Pairwise comparisons were performed to follow up on the significant effects. These analyses revealed that older adults evaluated their own level of functioning relative to their typical age peers more positively than younger adults and adolescents with regard to all seven domains of functioning $(p<.05)$. Older adults also evaluated their own level of functioning relative to their typical age peers more positively than children did for evaluations of attention, cognitive speed, and the ability to make new friends $(p<.05)$. Older adults and children did not differ with regard to evaluations of cognitive accuracy, and the abilities to memorize, to do mental arithmetic, and to assert oneself.

\section{Discussion}

Assumptions about what people are typically like in different phases of the life span guide age-graded attitudes and expectations toward others and oneself. Depending on one's own age or the age of one's interaction partner, these beliefs shape our thoughts and actions (e.g., Hess, 2006). In the present study, we investigated whether such beliefs about typical life span development differ among children, adolescents, younger adults, and older adults. We also addressed the questions as to the age at which consensual representations of life span development emerge, how accurate these representations are, and whether there are age group differences in the accuracy of these beliefs.

\section{Beliefs About Normal Development in 9-Year-Old Children}

Our findings clearly support the prediction that 9-year-olds hold beliefs about typical life span development that are distinct from those held by adolescents, younger adults, and older adults. This was evident in three respects: First, there were pronounced differences in the level of functioning that children versus the other three age groups regarded as typical throughout the life span. Second, between-person variation in subjective beliefs about typical development was substantially more pronounced within the group of 9-year-old children than within the other three age groups. In other words, there was less agreement about typical levels of functioning at given ages among 9-year-old children than among adolescents, younger adults, and older adults. Third, the shapes of typical developmental trajectories expected by children differed from those envisioned by the other three age groups. More specifically, for most of the investigated aspects of functioning, 9-year-olds tended to expect both less developmental growth in early phases and less developmental decline in later phases of the life span.

In addition to establishing age-related differences between subjective beliefs about normal development, the present research also aimed to address the validity (or accuracy) of these beliefs. To meet this aim, we performed biexponential latent growth analyses of the beliefs about the typical development of three selected cognitive abilities. Estimates from these analyses allowed us to evaluate the accuracy of subjective beliefs about normal development in two ways. First, we compared participants' subjective beliefs about typical development with empirical reference values obtained in a large-scale longitudinal investigation (McArdle et al., 2002). Second, we examined whether subjective beliefs about normal development mirror the theoretically and empirically wellestablished differences in the developmental trajectories of fluid and crystallized cognitive abilities (cf. Baltes, 1987; Cattell, 1971; Horn, 1989). As expected, the overlap of empirical reference values (McArdle et al., 2002) with children's beliefs about typical levels of functioning at different ages was limited and smaller than the corresponding overlap with developmental beliefs of adolescents and younger (but not older) adults. An interesting finding, 
however, was that children's beliefs already reflected some awareness of differences between developmental trajectories of fluid versus crystallized cognitive abilities. Despite pronounced divergence from the other three age groups in the expected magnitude of developmental change in fluid-cognitive abilities (i.e., memory and cognitive speed), 9-year-old children already showed indications of the belief that these abilities reach developmental peaks earlier in life and decline more steeply thereafter than crystallized cognitive abilities (i.e., general education/knowledge).

Overall, this pattern of findings is consistent with the notion that beliefs about normal development emerge in late middle childhood but have not yet been refined. Limited exposure of 9-year-olds to long-term developmental change, or to people of different ages, may be among the reasons for this. In addition, normative cultural scripts about typical development of functioning apparently have not yet been internalized by late middle childhood, which is consistent with research on the acquisition of cultural scripts about the normative sequencing of life events (e.g., Bohn \& Berntsen, 2008; Habermas, 2007).

Our results indicate that consensus in beliefs about normal development emerges earlier for some facets of functioning than for others. In the present study, children's beliefs about the typical development of mental arithmetic and of general education/knowledge were most similar to that of the older age groups. Possibly, experiences in school contexts may make the development of these aspects of functioning more salient and consciously accessible to 9-year-old children than other aspects of functioning. Children may thus be better able to evaluate their own and others' proficiency with regard to mental arithmetic and knowledge than with regard to other aspects of functioning. This, in turn, may facilitate the refinement of subjective beliefs about typical life span development of mental arithmetic and knowledge relative to other facets of cognitive or social functioning.

\section{Beliefs About Normal Development in Adolescents, Younger Adults, and Older Adults}

Adolescents showed far more consensus about typical development than children did. This finding supports the hypothesis that cultural scripts about normative development have been largely internalized by mid-adolescence (e.g., Bohn \& Berntsen, 2008; Habermas, 2007). Combined with the adolescents' own developmental experiences and observations, cultural scripts would contribute to the relatively consensual expectations about typical development of functioning, not only within adolescents but also among adolescents and adults of different ages. Indeed, we found that the 13- to 15-year-old adolescents held beliefs about typical levels of functioning in different periods of the life span that were more similar to those of younger and older adults than to the beliefs held by 9 -year-olds.

Consistent with our predictions, older adults reported the most optimistic expectations about adult development. This was particularly obvious with regard to expectations about typical levels of functioning in middle and early late adulthood and when compared with expectations held by children and adolescents. Reliable differences from beliefs held by younger adults were found as well, but less often. This pattern of older adults' more favorable expectations of typical adult development is in line with observations in earlier studies (e.g., Heckhausen, 1999; Lineweaver \& Hertzog, 1998).

Theoretically, two explanations seem possible for why older adults hold more favorable expectations of typical functional levels in middle and early late adulthood. Older adults' more positive beliefs could reflect either more accurate representations of typical adult development, arising from more extensive experience with developmental changes in middle and early late adulthood, or less accurate representations, reflecting a positive bias in the perception of life phases they have recently gone through or are currently in. Findings from the present study are more consistent with the latter option. Subjective beliefs about typical development held by adolescents and younger adults matched empirically observed performance trajectories better than older adults' beliefs did. It has been argued that older adults' optimistic beliefs about typical adult development may fulfill a self-enhancing function (Lineweaver \& Hertzog, 1998). Positive perceptions of adult functioning, however, can only be protective of self-worth if older adults perceive themselves to be as good or better than they perceive their typical age peer to be (see also Weiss, Sassenberg, \& Freund, 2013). Findings of the present study indeed showed that older participants evaluated their own functioning as being better than that of their typical age peers, and that these positive self-perceptions relative to perceptions of age peers were significantly different from those of younger adults and adolescents. Taken together, evidence of more favorable perceptions of typical functional levels in middle and early late adulthood and evidence of positive self-perception relative to perceptions of typical age peers are suggestive of self-worth protective tendencies in older adults. Such an interpretation is also consistent with research arguing that an increased motivation to maximize emotional well-being shapes cognitive processing in older adulthood (e.g., Carstensen \& Mikels, 2005). An interesting task for future research would be to directly investigate associations between participants' beliefs about typical development and their feelings of self-worth.

Although we believe that our attempt to evaluate the validity (accuracy) of subjective beliefs about normal development is an important contribution to the research field, we need to acknowledge that there are limitations to our approach. One is that our validity criteria stemmed from a study with only two measurement points and an interval of up to 10 years between measurement occasions. Another limitation is the possibility that the operationalization of the validation criteria may not overlap perfectly with the aspects of functioning that participants in the present investigation had in mind when reporting their beliefs about normal development. Using multiple validation criteria from several studies would be preferable in future studies. In addition, samples of middle-aged adults should be included to shed further light on adult age differences in subjective beliefs about life span development.

The present findings also indicate that older adults' more positive beliefs about adult development do not generalize across all aspects of functioning. The two exceptions to this pattern involved beliefs about the abilities to concentrate/attention and to have harmonious contacts to close friends, family, or acquaintances. Adolescents, younger adults, and older adults reported highly similar expectations of typical levels of functioning at different ages throughout the life span for these two aspects of functioning. It is possible that, for older adults, aging-related declines in oneself 
and in one's age peers are particularly noticeable and salient for the ability to concentrate/attention, and that this attenuates their tendency for positively biased conceptions of the life span development of this ability. A possible reason for older adults' not having more positive perceptions of the life span development of the ability to have harmonious contacts than the other age groups could be that all participants had relatively positive developmental expectations in this regard, that is, they expected this ability to remain relatively robust throughout adulthood and into late adulthood.

It is important to note that even though older adults expected comparatively higher levels of functioning in middle and older adulthood than younger age groups did for most of the investigated abilities, there was marked agreement of older adults with adolescents and younger adults regarding the shape of typical developmental trajectories of the investigated aspects of functioning. Proceeding from the results of biexponential latent growth analyses, we modeled, for selected cognitive abilities and separately for each age group of participants, six characteristics of the shape of the expected developmental trajectories. Results indicated high consensus among adolescents, younger adults, and older adults in their beliefs about the timing, direction, and magnitude of life span developmental change in these aspects of functioning. As in children, these beliefs also reflected awareness of differential developmental trajectories for fluid versus crystallized cognitive abilities in adolescents, younger adults, and older adults.

\section{Conclusions}

Overall, the findings from this study support the notion that beliefs about normal development have emerged by late middle childhood. Nine-year-old children already know that developmental trajectories may differ across different aspects of functioning (e.g., that fluid-cognitive abilities reach their developmental peak earlier, and decline more steeply thereafter than crystallizedcognitive abilities). Future research should extend the paradigm used in this study to include a more fine-grained assessment of earlier ages to delineate the age at which expectations about typical development are not yet available, and should directly investigate the psychological mechanisms that contribute to the acquisition and refinement of beliefs about typical development.

Our results also show that 9-year-old children have not yet formed a refined understanding of the timing, direction, and magnitude of developmental change. The pronounced increase in consensus with age peers from 9 years of age to mid-adolescence suggests that cultural scripts about age-normative development have been acquired by mid-adolescence. At that age, the accuracy of subjective beliefs about normal development (i.e., the correspondence to reference standards from empirically observed development) has reached a level that is comparable with that of younger adults, and larger than that of children or older adults. Except for a few aspects of functioning, older adults hold more optimistic expectations of typical levels of functioning in middle and early late adulthood than younger individuals do. The observed decline in correspondence with empirical reference values, compared with adolescents and young adults, together with older adults' more positive self-perceptions relative to perceptions of typical age peers speak for the possibility that self-worth enhancing biases contribute to older adults' optimistic beliefs about typical functional capacity in life phases that are close to, or correspond with, their own current age.

\section{References}

Baltes, P. B. (1987). Theoretical propositions of life-span developmental psychology: On the dynamics between growth and decline. Developmental Psychology, 23, 611-626. doi:10.1037/0012-1649.23.5.611

Baltes, P. B., Lindenberger, U., \& Staudinger, U. M. (1998). Life-span theory in developmental psychology. In R. M. Lerner (Ed.), Handbook of child psychology: Vol. 1. Theoretical Models of human development (5th ed., pp. 1029-1143). New York, NY: Wiley.

Bohn, A., \& Berntsen, D. (2008). Life story development in childhood: The development of life story abilities and the acquisition of cultural life scripts from late middle childhood to adolescence. Developmental Psychology, 44, 1135-1147. doi:10.1037/0012-1649.44.4.1135

Carstensen, L. L., \& Mikels, J. A. (2005). At the intersection of emotion and cognition: Aging and the positivity effect. Current Directions in Psychological Science, 14, 117-121. doi:10.1111/j.0963-7214.2005 .00348.x

Cattell, R. B. (1943). The measurement of adult intelligence. Psychological Bulletin, 40, 153-193. doi:10.1037/h0059973

Cattell, R. B. (1971). Abilities: Their structure, growth, and action. Boston, MA: Houghton Mifflin.

Cerella, J., \& Hale, S. (1994). The rise and fall in information-processing rates over the life span. Acta Psychologica, 86, 109-197. doi:10.1016/ 0001-6918(94)90002-7

Charles, S. T., \& Carstensen, L. L. (2010). Social and emotional aging. Annual Review of Psychology, 61, 383-409. doi:10.1146/annurev.psych .093008 .100448

Cole, D. A., Maxwell, S. E., Martin, J. M., Peeke, L. G., Seroczynski, A. D., Tram, J. M., . . Maschman, T. (2001). The development of multiple domains of child and adolescent self-concept: A cohort sequential longitudinal design. Child Development, 72, 1723-1746. doi: $10.1111 / 1467-8624.00375$

Erber, J. T., Szuchman, L. T., \& Prager, I. G. (1997). Forgetful but forgiven: How age and life style affect perceptions of memory failure. The Journals of Gerontology: Series B: Psychological Sciences and Social Sciences, 52, P303-P307. doi:10.1093/geronb/52B.6.P303

Friedman, W. J., \& Lyon, T. D. (2005). Development of temporalreconstructive abilities. Child Development, 76, 1202-1216. doi: 10.1111/j.1467-8624.2005.00844.x-i1

Habermas, T. (2007). How to tell a life: The development of the cultural concept of biography. Journal of Cognition and Development, 8, 1-31. doi:10.1207/s15327647jcd0801_1

Habermas, T., \& Bluck, S. (2000). Getting a life: The emergence of the life story in adolescence. Psychological Bulletin, 126, 748-769. doi: 10.1037/0033-2909.126.5.748

Heckhausen, J. (1999). Developmental regulation in adulthood: Agenormative and sociostructural constraints as adaptive challenges. New York, NY: Cambridge University Press.

Heckhausen, J., Dixon, R. A., \& Baltes, P. B. (1989). Gains and losses in development throughout adulthood as perceived by different adult age groups. Developmental Psychology, 25, 109-121. doi:10.1037/00121649.25.1.109

Hess, T. M. (2006). Attitudes toward aging and their effects on behavior. In J. Birren \& K. W. Schaie (Eds.), Handbook of the psychology of aging (6th ed., pp. 379-406). Amsterdam, Netherlands: Elsevier. doi:10.1016/ B978-012101264-9/50020-3

Horn, J. L. (1989). Models of intelligence. In R. L. Linn (Ed.), Intelligence: Measurement, theory, and public policy: Proceedings of a symposium in honor of Lloyd G. Humphreys (pp. 29-73). Champaign, IL: University of Illinois Press.

Kornadt, A. E., \& Rothermund, K. (2011). Contexts of aging: Assessing evaluative age stereotypes in different life domains. The Journals of 
Gerontology: Series B: Psychological Sciences and Social Sciences, 66, 547-556. doi:10.1093/geronb/gbr036

Lehrl, S., Merz, J., Burkhard, G., \& Fischer, S. (1991). Mehrfachwahl Wortschatz - Intelligenztest, MWT-A [Multiple-choice vocabulary intelligence test, MWT-A]. Göttingen, Germany: Hogrefe.

Li, S.-C., Lindenberger, U., Hommel, B., Aschersleben, G., Prinz, W., \& Baltes, P. B. (2004). Transformations in the couplings among intellectual abilities and constituent cognitive processes across the life span. Psychological Science, 15, 155-163. doi:10.1111/j.0956-7976.2004.01503003.x

Lineweaver, T. T., \& Hertzog, C. (1998). Adults' efficacy and control beliefs regarding memory and aging: Separating general from personal beliefs. Aging, Neuropsychology, and Cognition, 5, 264-296. doi: 10.1076/anec.5.4.264.771

Luong, G., Charles, S. T., \& Fingerman, K. L. (2011). Better with age: Social relationships across adulthood. Journal of Social and Personal Relationships, 28, 9-23. doi:10.1177/0265407510391362

McArdle, J. J., Ferrer-Caja, E., Hamagami, F., \& Woodcock, R. W. (2002). Comparative longitudinal structural analyses of the growth and decline of multiple intellectual abilities over the life span. Developmental Psychology, 38, 115-142. doi:10.1037/0012-1649.38.1.115

Muthén, B. O., \& Muthén, L. K. (1998-2011). Mplus User's Guide. Sixth Edition. Los Angeles, CA: Muthén \& Muthén.

Rosseel, Y. (2012). lavaan: An R package for structural equation modeling. Journal of Statistical Software, 48, 1-36.

Rothermund, K., \& Brandtstädter, J. (2003). Age stereotypes and selfviews in later life: Evaluating rival assumptions. International Journal of Behavioral Development, 27, 549-554. doi:10.1080/ 01650250344000208
Rubin, D. C., \& Berntsen, D. (2003). Life scripts help to maintain autobiographical memories of highly positive, but not highly negative, events. Memory \& Cognition, 31, 1-14. doi:10.3758/BF03196077

Schaefer, S., Riediger, M., Li, S.-C., \& Lindenberger, U. (2013). Too easy, too hard, or just right: Task-difficulty choices differ by age and gender. Manuscript in preparation.

Schorsch, S. (1992). Die Entwicklung von Konzepten über das Lebensalter bei Kindern und Jugendlichen [Development of concepts of life phases in children and adolescents]. Münster, Germany: Waxmann.

Stipek, D., \& Iver, D. M. (1989). Developmental change in children's assessment of intellectual competence. Child Development, 60, 521538. doi:10.2307/1130719

Thorndike, R. L., Hagen, E., \& Lorge, I. (1954). Cognitive Abilities Test Boston, MA: Houghton Mifflin.

Voelkle, M. C. (2007). Latent growth curve modeling as an integrative approach to the analysis of change. Psychology Science, 49, 375414.

Wechsler, D. (1981). Wechsler Adult Intelligence Scale - Revised (WAIS$R)$. New York, NY: Psychological Corporation.

Weiss, D., Sassenberg, K., \& Freund, A. M. (2013). When feeling different pays off: How older adults can counteract negative age-related information. Psychology and Aging, 28, 1140-1146. doi:10.1037/a0033811

Woodcock, R. W., \& Johnson, M. B. (1989). Woodcock-Johnson PsychoEducational Battery - Revised. Allen, TX: DLM Teaching Resources.

Wrzus, C., Hänel, M., Wagner, J., \& Neyer, F. J. (2013). Social network change and life events across the lifespan: A meta-analysis. Psychological Bulletin, 139, 53-80. doi:10.1037/a0028601 


\section{Appendix A}

Pairwise Comparisons of Beliefs About Typical Levels of Functioning Held by Older Adults (OA) With Those Held by the Other Age Groups

\begin{tabular}{|c|c|c|c|c|c|c|c|c|c|c|c|}
\hline & \multicolumn{2}{|c|}{ Intercept ${ }^{\mathrm{a}}$} & \multicolumn{3}{|c|}{ Children vs. OA } & \multicolumn{3}{|c|}{ Adolescents vs. OA } & \multicolumn{3}{|c|}{ Younger adults vs. OA } \\
\hline & $B$ & $S E$ & $B$ & $S E$ & $p$ & $B$ & $S E$ & $p$ & $B$ & $S E$ & $p$ \\
\hline \multicolumn{12}{|c|}{ Ability to memorize at age } \\
\hline 5 & 4.475 & 0.443 & -1.892 & 0.644 & 0.004 & 1.025 & 0.627 & 0.104 & 0.675 & 0.627 & 0.283 \\
\hline 10 & 5.950 & 0.371 & -1.644 & 0.539 & 0.003 & 0.625 & 0.525 & 0.236 & 0.925 & 0.525 & 0.080 \\
\hline 15 & 7.150 & 0.326 & -1.956 & 0.474 & 0.000 & 0.150 & 0.462 & 0.746 & 0.625 & 0.462 & 0.178 \\
\hline 20 & 8.025 & 0.326 & -2.053 & 0.473 & 0.000 & -0.550 & 0.461 & 0.234 & 0.625 & 0.461 & 0.177 \\
\hline 30 & 8.150 & 0.336 & -2.122 & 0.488 & 0.000 & -1.025 & 0.475 & 0.033 & -0.100 & 0.475 & 0.834 \\
\hline 40 & 7.900 & 0.339 & -1.706 & 0.492 & 0.001 & -1.475 & 0.479 & 0.002 & -0.625 & 0.479 & 0.194 \\
\hline 50 & 7.025 & 0.319 & -1.414 & 0.463 & 0.003 & -1.625 & 0.451 & 0.000 & -0.650 & 0.451 & 0.152 \\
\hline 60 & 6.200 & 0.325 & -0.839 & 0.472 & 0.078 & -1.675 & 0.460 & 0.000 & -0.800 & 0.460 & 0.084 \\
\hline 70 & 5.050 & 0.326 & -0.328 & 0.474 & 0.490 & -1.675 & 0.461 & 0.000 & -1.150 & 0.461 & 0.014 \\
\hline $85+$ & 3.350 & 0.319 & 0.900 & 0.463 & 0.054 & -1.150 & 0.451 & 0.012 & -0.800 & 0.451 & 0.078 \\
\hline \multicolumn{12}{|c|}{ General education/knowledge at age } \\
\hline 5 & 2.050 & 0.141 & -0.133 & 0.204 & 0.515 & -0.675 & 0.199 & 0.001 & -0.550 & 0.199 & 0.006 \\
\hline 10 & 3.700 & 0.227 & 0.522 & 0.330 & 0.116 & -0.825 & 0.321 & 0.011 & -0.625 & 0.321 & 0.054 \\
\hline 15 & 5.200 & 0.277 & 0.133 & 0.403 & 0.741 & -0.300 & 0.392 & 0.445 & -0.225 & 0.392 & 0.567 \\
\hline 20 & 7.100 & 0.309 & -0.822 & 0.449 & 0.069 & -1.000 & 0.437 & 0.023 & -0.350 & 0.437 & 0.424 \\
\hline 30 & 8.325 & 0.320 & -1.519 & 0.465 & 0.001 & -1.500 & 0.453 & 0.001 & -0.725 & 0.453 & 0.112 \\
\hline 40 & 8.800 & 0.328 & -1.689 & 0.477 & 0.001 & -1.175 & 0.464 & 0.012 & -0.650 & 0.464 & 0.163 \\
\hline 50 & 9.150 & 0.318 & -1.872 & 0.461 & 0.000 & -1.525 & 0.449 & 0.001 & -0.775 & 0.449 & 0.086 \\
\hline 60 & 8.900 & 0.327 & -1.761 & 0.476 & 0.000 & -1.500 & 0.463 & 0.001 & -0.900 & 0.463 & 0.054 \\
\hline 70 & 8.075 & 0.365 & -0.964 & 0.530 & 0.071 & -0.950 & 0.516 & 0.068 & -1.050 & 0.516 & 0.044 \\
\hline $85+$ & 6.675 & 0.442 & -0.064 & 0.643 & 0.921 & -0.250 & 0.626 & 0.690 & -0.875 & 0.626 & 0.164 \\
\hline \multicolumn{12}{|c|}{ Cognitive speed at age } \\
\hline 5 & 3.750 & 0.408 & -0.861 & 0.592 & 0.148 & 0.625 & 0.577 & 0.280 & 1.050 & 0.577 & 0.071 \\
\hline 10 & 5.950 & 0.379 & -1.172 & 0.550 & 0.035 & 0.700 & 0.535 & 0.193 & 1.000 & 0.535 & 0.064 \\
\hline 15 & 7.550 & 0.302 & -2.467 & 0.439 & 0.000 & 0.200 & 0.428 & 0.641 & 0.450 & 0.428 & 0.294 \\
\hline 20 & 8.325 & 0.310 & -2.408 & 0.451 & 0.000 & -0.150 & 0.439 & 0.733 & 0.350 & 0.439 & 0.427 \\
\hline 30 & 8.750 & 0.304 & -2.778 & 0.442 & 0.000 & -1.050 & 0.431 & 0.016 & -0.675 & 0.431 & 0.119 \\
\hline 40 & 8.425 & 0.315 & -2.647 & 0.457 & 0.000 & -1.275 & 0.445 & 0.005 & -1.050 & 0.445 & 0.020 \\
\hline 50 & 7.700 & 0.282 & -2.144 & 0.410 & 0.000 & -1.500 & 0.399 & 0.000 & -1.075 & 0.399 & 0.008 \\
\hline 60 & 6.725 & 0.292 & -1.586 & 0.425 & 0.000 & -1.475 & 0.413 & 0.000 & -1.125 & 0.413 & 0.007 \\
\hline 70 & 5.350 & 0.299 & -0.739 & 0.434 & 0.091 & -1.125 & 0.423 & 0.009 & -1.125 & 0.423 & 0.009 \\
\hline $85+$ & 3.725 & 0.314 & 0.247 & 0.456 & 0.588 & -0.700 & 0.443 & 0.116 & -0.900 & 0.443 & 0.044 \\
\hline \multicolumn{12}{|c|}{ Cognitive accuracy at age. } \\
\hline 5 & 2.275 & 0.292 & 0.447 & 0.424 & 0.293 & 1.225 & 0.412 & 0.003 & 0.550 & 0.412 & 0.184 \\
\hline 10 & 4.000 & 0.323 & 0.806 & 0.469 & 0.088 & 1.175 & 0.457 & 0.011 & 1.025 & 0.457 & 0.026 \\
\hline 15 & 5.500 & 0.323 & -0.139 & 0.469 & 0.768 & 0.775 & 0.457 & 0.092 & 0.925 & 0.457 & 0.045 \\
\hline 20 & 7.075 & 0.328 & -1.047 & 0.477 & $\mathbf{0 . 0 3 0}$ & 0.500 & 0.464 & 0.283 & 0.900 & 0.464 & 0.054 \\
\hline 30 & 8.075 & 0.327 & -1.769 & 0.474 & 0.000 & -0.525 & 0.462 & 0.257 & 0.375 & 0.462 & 0.418 \\
\hline 40 & 8.525 & 0.322 & -1.997 & 0.467 & 0.000 & -1.075 & 0.455 & 0.019 & -0.425 & 0.455 & 0.351 \\
\hline 50 & 8.275 & 0.332 & -2.386 & 0.483 & 0.000 & -1.650 & 0.470 & 0.001 & -1.075 & 0.470 & 0.024 \\
\hline 60 & 7.500 & 0.338 & -1.417 & 0.491 & 0.004 & -1.525 & 0.478 & 0.002 & -1.225 & 0.478 & 0.011 \\
\hline 70 & 6.350 & 0.351 & -0.794 & 0.510 & 0.122 & -1.250 & 0.497 & 0.013 & -1.225 & 0.497 & 0.015 \\
\hline $85+$ & 4.550 & 0.414 & 0.617 & 0.601 & 0.307 & -0.225 & 0.585 & 0.701 & -0.800 & 0.585 & 0.174 \\
\hline \multicolumn{12}{|c|}{ Mental arithmetic at age. } \\
\hline 5 & 1.725 & 0.199 & 0.275 & 0.289 & 0.343 & 0.475 & 0.282 & 0.094 & 0.200 & 0.282 & 0.479 \\
\hline 10 & 4.875 & 0.306 & -0.125 & 0.445 & 0.779 & -0.325 & 0.433 & 0.454 & 0.275 & 0.433 & 0.526 \\
\hline 15 & 6.775 & 0.304 & -0.692 & 0.441 & 0.119 & -0.200 & 0.430 & 0.642 & 0.625 & 0.430 & 0.148 \\
\hline 20 & 8.025 & 0.300 & -0.886 & 0.435 & 0.043 & -0.725 & 0.424 & 0.089 & 0.025 & 0.424 & 0.953 \\
\hline 30 & 8.100 & 0.284 & -0.517 & 0.412 & 0.212 & -1.225 & 0.401 & 0.003 & -0.800 & 0.401 & 0.048 \\
\hline 40 & 7.725 & 0.318 & -0.142 & 0.462 & 0.759 & -1.175 & 0.449 & 0.010 & -1.100 & 0.449 & 0.016 \\
\hline 50 & 7.150 & 0.332 & -0.206 & 0.482 & 0.670 & -1.400 & 0.469 & 0.003 & -1.325 & 0.469 & 0.005 \\
\hline 60 & 6.275 & 0.345 & 0.114 & 0.501 & 0.820 & -1.175 & 0.488 & 0.017 & -1.350 & 0.488 & 0.006 \\
\hline 70 & 5.225 & 0.349 & 0.581 & 0.507 & 0.254 & -1.050 & 0.494 & 0.035 & -1.375 & 0.494 & 0.006 \\
\hline $85+$ & 3.700 & 0.363 & 1.244 & $\mathbf{0 . 5 2 8}$ & 0.020 & -0.750 & 0.514 & 0.146 & -0.900 & 0.514 & 0.082 \\
\hline
\end{tabular}


Appendix A (continued)

\begin{tabular}{|c|c|c|c|c|c|c|c|c|c|c|c|}
\hline & \multicolumn{2}{|c|}{ Intercept $^{\mathrm{a}}$} & \multicolumn{3}{|c|}{ Children vs. OA } & \multicolumn{3}{|c|}{ Adolescents vs. OA } & \multicolumn{3}{|c|}{ Younger adults vs. OA } \\
\hline & $B$ & $S E$ & $B$ & $S E$ & $p$ & $B$ & $S E$ & $p$ & $B$ & $S E$ & $p$ \\
\hline \multicolumn{12}{|c|}{ Ability to concentrate/attention at age.. } \\
\hline 5 & 3.250 & 0.369 & -0.417 & 0.536 & 0.438 & -0.200 & 0.522 & 0.702 & -0.525 & 0.522 & 0.316 \\
\hline 10 & 4.975 & 0.361 & 0.025 & 0.525 & 0.962 & 0.075 & 0.511 & 0.883 & -0.175 & 0.511 & 0.732 \\
\hline 15 & 6.425 & 0.333 & -1.036 & 0.484 & 0.034 & -0.325 & 0.471 & 0.491 & -0.150 & 0.471 & 0.750 \\
\hline 20 & 7.925 & 0.334 & -1.731 & 0.485 & 0.000 & 0.000 & 0.472 & 1.000 & 0.575 & 0.472 & 0.225 \\
\hline 30 & 8.650 & 0.321 & -2.483 & 0.467 & 0.000 & -0.700 & 0.454 & 0.126 & -0.100 & 0.454 & 0.826 \\
\hline 40 & 8.500 & 0.324 & -2.000 & 0.471 & 0.000 & -0.700 & 0.458 & 0.129 & -0.150 & 0.458 & 0.744 \\
\hline 50 & 7.725 & 0.324 & -1.503 & 0.471 & 0.002 & -0.625 & 0.459 & 0.175 & -0.325 & 0.459 & 0.480 \\
\hline 60 & 6.800 & 0.352 & -0.217 & 0.511 & 0.672 & -0.325 & 0.498 & 0.515 & -0.425 & 0.498 & 0.394 \\
\hline 70 & 5.550 & 0.361 & 0.756 & 0.524 & 0.152 & 0.125 & 0.510 & 0.807 & -0.525 & 0.510 & 0.305 \\
\hline $85+$ & 3.650 & 0.379 & 2.239 & 0.551 & 0.000 & 1.025 & 0.536 & 0.058 & 0.000 & 0.536 & 1.000 \\
\hline \multicolumn{12}{|c|}{ Harmonious contacts to close friends, family, or acquaintances at age ... } \\
\hline 5 & 5.825 & 0.487 & -2.408 & 0.708 & 0.001 & 0.025 & 0.689 & 0.971 & -0.325 & 0.689 & 0.638 \\
\hline 10 & 6.725 & 0.402 & -2.086 & 0.583 & 0.000 & 0.100 & 0.568 & 0.860 & -0.600 & 0.568 & 0.292 \\
\hline 15 & 6.675 & 0.378 & -1.758 & 0.550 & 0.002 & 0.100 & 0.535 & 0.852 & -0.775 & 0.535 & 0.150 \\
\hline 20 & 7.250 & 0.337 & -2.250 & 0.490 & 0.000 & 0.225 & 0.477 & 0.638 & 0.425 & 0.477 & 0.375 \\
\hline 30 & 8.000 & 0.326 & -2.611 & 0.473 & 0.000 & 0.025 & 0.461 & 0.957 & 0.525 & 0.461 & 0.256 \\
\hline 40 & 8.125 & 0.359 & -2.125 & 0.521 & 0.000 & -0.150 & 0.507 & 0.768 & 0.200 & 0.507 & 0.694 \\
\hline 50 & 8.175 & 0.342 & -2.619 & 0.497 & 0.000 & -0.425 & 0.484 & 0.381 & -0.500 & 0.484 & 0.303 \\
\hline 60 & 8.075 & 0.357 & -2.603 & 0.518 & 0.000 & -0.550 & 0.504 & 0.277 & -0.725 & 0.504 & 0.153 \\
\hline 70 & 7.350 & 0.395 & -1.933 & 0.574 & 0.001 & 0.275 & 0.558 & 0.623 & -0.575 & 0.558 & 0.305 \\
\hline $85+$ & 6.175 & 0.425 & -0.842 & 0.617 & 0.174 & 0.775 & 0.600 & 0.199 & -0.300 & 0.600 & 0.618 \\
\hline \multicolumn{12}{|c|}{ Ability to hold one's ground against others/to assert oneself at age . . } \\
\hline 5 & 3.175 & 0.434 & 0.769 & 0.630 & 0.224 & 1.100 & 0.613 & 0.075 & 0.000 & 0.613 & 1.000 \\
\hline 10 & 5.300 & 0.363 & -0.356 & 0.527 & 0.501 & -0.075 & 0.513 & 0.884 & -0.775 & 0.513 & 0.133 \\
\hline 15 & 7.025 & 0.356 & -1.386 & 0.517 & 0.008 & 0.075 & 0.503 & 0.882 & -1.325 & 0.503 & 0.009 \\
\hline 20 & 8.475 & 0.328 & -2.781 & 0.477 & 0.000 & -0.700 & 0.464 & 0.133 & -0.925 & 0.464 & 0.048 \\
\hline 30 & 9.200 & 0.321 & -3.450 & 0.466 & 0.000 & -1.225 & 0.454 & 0.008 & -0.550 & 0.454 & 0.227 \\
\hline 40 & 9.150 & 0.328 & -2.983 & 0.477 & 0.000 & -1.500 & 0.464 & 0.001 & -0.475 & 0.464 & 0.307 \\
\hline 50 & 8.625 & 0.326 & -2.958 & 0.473 & 0.000 & -1.425 & 0.461 & 0.002 & -0.575 & 0.461 & 0.214 \\
\hline 60 & 7.450 & 0.340 & -2.172 & 0.494 & 0.000 & -1.250 & 0.481 & 0.010 & -0.625 & 0.481 & 0.196 \\
\hline 70 & 6.300 & 0.364 & -1.133 & 0.529 & 0.034 & -1.175 & 0.515 & 0.024 & -0.850 & 0.515 & 0.101 \\
\hline $85+$ & 4.050 & 0.391 & 0.950 & 0.568 & 0.097 & -0.125 & 0.553 & 0.822 & -0.050 & 0.553 & 0.928 \\
\hline \multicolumn{12}{|c|}{ Ability to get to know new people at age... } \\
\hline 5 & 4.375 & 0.486 & -0.153 & 0.707 & 0.829 & 2.750 & 0.688 & 0.000 & 2.850 & 0.688 & 0.000 \\
\hline 10 & 6.225 & 0.380 & -0.753 & 0.552 & 0.174 & 1.550 & $\mathbf{0 . 5 3 7}$ & 0.004 & 1.725 & $\mathbf{0 . 5 3 7}$ & 0.002 \\
\hline 15 & 7.725 & 0.347 & -1.864 & 0.504 & 0.000 & 0.550 & 0.490 & 0.264 & -0.425 & 0.490 & 0.387 \\
\hline 20 & 8.525 & 0.304 & -2.219 & 0.441 & 0.000 & 0.375 & 0.430 & 0.384 & 0.025 & 0.430 & 0.954 \\
\hline 30 & 8.625 & 0.302 & -2.597 & 0.439 & 0.000 & -0.750 & 0.427 & 0.081 & -0.775 & 0.427 & 0.071 \\
\hline 40 & 8.325 & 0.318 & -1.992 & 0.463 & 0.000 & -1.025 & 0.450 & 0.024 & -1.475 & 0.450 & 0.001 \\
\hline 50 & 7.500 & 0.345 & -1.167 & 0.501 & 0.021 & -1.100 & 0.488 & 0.026 & -1.750 & 0.488 & 0.000 \\
\hline 60 & 6.750 & 0.354 & -0.889 & 0.515 & 0.086 & -0.950 & 0.501 & 0.060 & -1.875 & 0.501 & 0.000 \\
\hline 70 & 5.300 & 0.355 & 0.589 & 0.515 & 0.255 & -0.550 & 0.502 & 0.275 & -1.400 & 0.502 & 0.006 \\
\hline $85+$ & 3.550 & 0.373 & 2.283 & 0.542 & 0.000 & -0.075 & 0.528 & 0.887 & -0.750 & 0.528 & 0.157 \\
\hline \multicolumn{12}{|c|}{ Ability to solve conflicts at age... } \\
\hline 5 & 1.925 & 0.261 & 0.853 & 0.380 & 0.026 & -0.075 & 0.370 & 0.839 & 0.050 & 0.370 & 0.893 \\
\hline 10 & 3.525 & 0.305 & 2.114 & 0.443 & 0.000 & 0.475 & 0.432 & 0.273 & -0.025 & 0.432 & 0.954 \\
\hline 15 & 5.125 & 0.327 & 0.403 & 0.475 & 0.398 & 1.175 & 0.462 & 0.012 & -0.250 & 0.462 & 0.590 \\
\hline 20 & 7.100 & 0.330 & -0.906 & 0.480 & 0.061 & 0.250 & 0.467 & 0.593 & 0.350 & 0.467 & 0.454 \\
\hline 30 & 8.300 & 0.303 & -1.828 & 0.440 & 0.000 & -0.325 & 0.428 & 0.449 & 0.675 & 0.428 & 0.117 \\
\hline 40 & 8.975 & 0.322 & -1.836 & 0.468 & 0.000 & -1.025 & 0.456 & 0.026 & -0.075 & 0.456 & 0.869 \\
\hline 50 & 8.850 & 0.290 & -2.322 & 0.422 & 0.000 & -1.350 & 0.410 & 0.001 & -0.350 & 0.410 & 0.395 \\
\hline 60 & 8.250 & 0.337 & -1.500 & 0.490 & 0.003 & -1.175 & 0.477 & 0.015 & -0.500 & 0.477 & 0.296 \\
\hline 70 & 6.675 & 0.375 & -0.481 & 0.544 & 0.379 & -0.625 & 0.530 & 0.240 & -0.525 & 0.530 & 0.323 \\
\hline $85+$ & 4.350 & 0.407 & 1.650 & 0.591 & 0.006 & 0.400 & 0.576 & 0.488 & 0.675 & 0.576 & 0.243 \\
\hline
\end{tabular}

Note. Significant differences to beliefs of older adults are highlighted in bold font $(p<.05)$. OA $=$ older adults.

${ }^{\mathrm{a}}$ Intercept represents average beliefs reported by older adults. All intercept estimates at $p<.001$. 


\section{Appendix B}

Parameter Estimates in Biexponential Latent Growth Modeling of Beliefs About the Normal Development of the Ability to Memorize

\begin{tabular}{|c|c|c|c|c|c|c|}
\hline & Estimate & $S E$ & $p$ & Variance & $S E$ & $p$ \\
\hline Intercept & $1.290\left(b_{0}\right.$ Children $)$ & 1.076 & .230 & $14.318 \operatorname{Var}\left(\zeta_{0 i}\right)$ & 5.839 & .014 \\
\hline Adolescents $^{\mathrm{a}}$ & $-4.138\left(b_{0}\right.$ Adolescents $)$ & 1.302 & .001 & & & \\
\hline Young adults ${ }^{\mathrm{a}}$ & -4.793 ( $b_{0}$ Young Adults $)$ & 1.516 & .002 & & & \\
\hline Older adults ${ }^{\mathrm{a}}$ & $-2.876\left(b_{0}\right.$ Older Adults $)$ & 1.270 & .024 & & & \\
\hline \multicolumn{7}{|l|}{ Part 1 (growth) } \\
\hline$b_{1}$ & $11.539\left(b_{1 \text { Children }}\right)$ & 2.664 & .000 & 102.223 $\operatorname{Var}\left(\zeta_{1 i}\right)$ & 32.443 & .002 \\
\hline Adolescents ${ }^{\mathrm{a}}$ & $8.676\left(b_{1 \text { Adolescents }}\right)$ & 2.489 & .000 & & & \\
\hline Young adults ${ }^{\mathrm{a}}$ & $12.746\left(b_{1}\right.$ Young Adults $)$ & 2.667 & .000 & & & \\
\hline Older adults $^{\mathrm{a}}$ & $9.732\left(b_{1}\right.$ older Adults $)$ & 2.673 & .000 & & & \\
\hline$b_{3}$ & .016 & .005 & .001 & & & \\
\hline \multicolumn{7}{|l|}{ Part 2 (decline) } \\
\hline$b_{2}$ & $12.322\left(b_{2 \text { Children }}\right)$ & 3.158 & .000 & $100.658 \operatorname{Var}\left(\zeta_{2 i}\right)$ & 44.233 & .023 \\
\hline Adolescents ${ }^{\mathrm{a}}$ & $1.456\left(b_{2}\right.$ Adolescents) & 2.734 & .594 & & & \\
\hline Young adults $^{\mathrm{a}}$ & $6.012\left(b_{2 \text { Young Adults }}\right)$ & 3.273 & .066 & & & \\
\hline Older adults $^{\mathrm{a}}$ & $6.143\left(b_{2}\right.$ older Adults $)$ & 3.042 & .043 & & & \\
\hline$b_{4}$ & .058 & .007 & .000 & & & \\
\hline
\end{tabular}

Note. Beliefs about the typical ability to memorize at different ages were modeled with the biexponential latent growth model shown in Equations 1 and 2 .

${ }^{\text {a }}$ Dummy coded, reference group $=$ children .

\section{Appendix C}

Parameter Estimates in Biexponential Latent Growth Modeling of Beliefs About the Normal Development of Cognitive Speed

\begin{tabular}{|c|c|c|c|c|c|c|}
\hline & Estimate & $S E$ & $p$ & Variance & $S E$ & $p$ \\
\hline Intercept & $2.022\left(b_{0 \text { Children }}\right)$ & .826 & .014 & $10.051 \operatorname{Var}\left(\zeta_{0 i}\right)$ & 3.581 & .005 \\
\hline Adolescents $^{\mathrm{a}}$ & $-3.161\left(b_{0 \text { Adolescents }}\right)$ & 1.102 & .004 & & & \\
\hline Young adults ${ }^{\mathrm{a}}$ & -3.507 ( $\left.b_{0 \text { Young Adults }}\right)$ & 1.186 & .003 & & & \\
\hline Older adults ${ }^{\mathrm{a}}$ & $-2.188\left(b_{0}\right.$ Older Adults $)$ & 1.085 & .044 & & & \\
\hline \multicolumn{7}{|l|}{ Part 1 (growth) } \\
\hline$b_{1}$ & $10.850\left(b_{1 \text { Children }}\right)$ & 3.268 & .001 & $87.528 \operatorname{Var}\left(\zeta_{1 i}\right)$ & 40.966 & .033 \\
\hline Adolescents ${ }^{\mathrm{a}}$ & $11.389\left(b_{1}\right.$ & 3.129 & .000 & & & \\
\hline Young adults ${ }^{\mathrm{a}}$ & 13.076 (b 1 Young Adults $)$ & 3.351 & .000 & & & \\
\hline Older adults ${ }^{\mathrm{a}}$ & $12.423\left(b_{1}\right.$ Older Adults $)$ & .006 & .001 & & & \\
\hline$b_{3}$ & .020 & .006 & .001 & & & \\
\hline \multicolumn{7}{|l|}{ Part 2 (decline) } \\
\hline$b_{2}$ & $11.876\left(b_{2 \text { Children }}\right)$ & 3.660 & .001 & $88.159 \operatorname{Var}\left(\zeta_{2 i}\right)$ & 49.122 & .073 \\
\hline Adolescents ${ }^{\mathrm{a}}$ & $7.583\left(b_{2}\right.$ Adelescents $)$ & 3.676 & .039 & & & \\
\hline Young adults $^{\mathrm{a}}$ & 8.781 ( $\left.b_{2 \text { Young Adults }}\right)$ & 4.020 & .029 & & & \\
\hline Older adults $^{\mathrm{a}}$ & $11.603\left(b_{2}\right.$ older Adults $)$ & 4.215 & .006 & & & \\
\hline$b_{4}$ & .060 & .009 & .000 & & & \\
\hline
\end{tabular}

Note. Beliefs about the typical cognitive speed at different ages were modeled with the biexponential latent growth model shown in Equations 1 and 2.

${ }^{\text {a }}$ Dummy coded, reference group $=$ children . 


\section{Appendix D}

Parameter Estimates in Biexponential Latent Growth Modeling of Beliefs About the Normal Development of General Education/Knowledge

\begin{tabular}{|c|c|c|c|c|c|c|}
\hline & Estimate & $S E$ & $p$ & Variance & $S E$ & $p$ \\
\hline Intercept & $2.040\left(b_{0}\right.$ Children $)$ & 2.470 & .409 & $47.722 \operatorname{Var}\left(\zeta_{0 i}\right)$ & 40.560 & .239 \\
\hline Adolescents $^{\mathrm{a}}$ & $-1.280\left(b_{0}\right.$ Adolescents $)$ & 1.783 & .473 & & & \\
\hline Young adults ${ }^{\mathrm{a}}$ & -4.077 ( $\left.b_{0 \text { Young Adults }}\right)$ & 2.632 & .121 & & & \\
\hline Older adults ${ }^{\mathrm{a}}$ & $-2.448\left(b_{0}\right.$ older Adults $)$ & 2.360 & .299 & & & \\
\hline \multicolumn{7}{|l|}{ Part 1 (growth) } \\
\hline$b_{1}$ & $18.572\left(b_{1 \text { Children }}\right)$ & 15.589 & .233 & $382.703 \operatorname{Var}\left(\zeta_{1 i}\right)$ & 465.343 & .411 \\
\hline Adolescents $^{\mathrm{a}}$ & $5.109\left(b_{1 \text { Adolescents }}\right)$ & 6.273 & .415 & & & \\
\hline Young adults $^{\mathrm{a}}$ & 14.579 ( $b_{1}$ Young Adults $)$ & 11.183 & .192 & & & \\
\hline Older adults $^{\mathrm{a}}$ & $12.369\left(b_{1}\right.$ Older Adults $)$ & 10.204 & .225 & & & \\
\hline$b_{3}$ & .014 & .010 & .158 & & & \\
\hline \multicolumn{7}{|l|}{ Part 2 (decline) } \\
\hline$b_{2}$ & $20.049\left(b_{2}\right.$ Children $)$ & 17.350 & .248 & $194.758 \operatorname{Var}\left(\zeta_{2 i}\right)$ & 412.181 & .637 \\
\hline Adolescents $^{\mathrm{a}}$ & $5.400\left(b_{2}\right.$ Adolescents $)$ & 5.788 & .351 & & & \\
\hline Young adults $^{\mathrm{a}}$ & 12.693 ( $b_{2}$ Young Adults $)$ & 12.540 & .311 & & & \\
\hline Older adults $^{\mathrm{a}}$ & $11.624\left(b_{2}\right.$ Older Adults $)$ & 11.129 & .296 & & & \\
\hline$b_{4}$ & .034 & .010 & .001 & & & \\
\hline
\end{tabular}

Note. Beliefs about the typical levels of general education/knowledge at different ages were modeled with the biexponential latent growth model shown in Equations 1 and 2.

${ }^{\mathrm{a}}$ Dummy coded, reference group $=$ children. 